\title{
Lokale Effekte der Reibung zwischen Pkw-Reifen und Fahrbahn
}

\author{
Vom Fachbereich Maschinenbau \\ der Technischen Universität Darmstadt \\ zur \\ Erlangung des Grades eines Doktor-Ingenieurs (Dr.-Ing.) \\ genehmigte \\ Dissertation
}

vorgelegt von

Dipl.-Ing. Markus Fach

aus Stuttgart

\author{
Berichterstatter: Prof. Dr.-Ing. Bert Breuer \\ Mitberichterstatter: Prof. Dipl.-Ing. Bernhard Ewald \\ Tag der Einreichung: $\quad$ 8. April 1999 \\ Tag der mündlichen Prüfung: $\quad$ 23. Juni 1999
}

Darmstadt 1999

D 17 


\section{Vorwort}

Die vorliegende Arbeit entstand während meiner Zeit als Wissenschaftlicher Mitarbeiter am Fachgebiet Fahrzeugtechnik der Technischen Universität Darmstadt. Zum Teil sind Ergebnisse aus meiner Tätigkeit im Referat Fahrzeug / Fahrbahn der Bundesanstalt für Straßenwesen in Bergisch Gladbach enthalten.

An erster Stelle gilt mein Dank dem Leiter des Fachgebiets Fahrzeugtechnik, Herrn Professor Dr.Ing. Bert Breuer, der mir die Bearbeitung der Forschungsaufgabe übertragen hat, die dieser Arbeit zugrunde liegt. Für die wissenschaftliche Betreuung der Arbeit, die fachliche Anleitung und besonders für die von ihm gewährte Selbständigkeit bin ich sehr dankbar. Herrn Prof. Dipl.-Ing. Bernhard Ewald danke ich für die Übernahme des Koreferats.

Der Leitung der Bundesanstalt für Straßenwesen sage ich Dank für die freundliche Überlassung eines Großprüfstand für meine Messungen. Besonders der Prüfstandsbelegschaft, die für mich schon in meiner Zeit als Angehöriger des Hauses weit über das normale Maß hinaus Einsatz gezeigt hat, gebührt mein Dank.

Den studentischen Mitarbeitern, ohne die das Gelingen der Arbeit unmöglich gewesen wäre, danke ich ebenfalls. Meinen Vorgängern Herrn Dr.-Ing. Jörg Supke und Herrn Dr.-Ing. Thomas Bachmann danke ich für die Schaffung der fachlichen Grundlagen dieser Arbeit. Ebenso gilt mein Dank den Kollegen des Fachgebiets Fahrzeugtechnik sowie den Werkstätten für die immer engagierte Unterstützung. Besonders danke ich meinem Kollegen und engen Partner auf dem gleichen Forschungsgebiet, Herrn Dr.-Ing. Volker Bachmann, der durch seine speziellen persönlichen Eigenschaften ein großes Maß zur guten Zusammenarbeit in unserem Team beigetragen hat.

Der Deutschen Forschungsgemeinschaft gilt mein Dank für die finanzielle Förderung des Projekts im Rahmen des Sonderforschungsbereichs 241 „IMES“ an der TU Darmstadt. Der DaimlerChrysler AG danke ich für die Unterstützung bei dem Erwerb und dem Einsatz einer Kraftmeßfelge. Der Continental AG sage ich Dank für wertvolle Simulationsrechnungen. Schließlich bedanke ich mich bei der BMW AG und der Siemens AG für den Informationsaustausch, der für mich sehr motivierend und fruchtbar war. 


\section{Inhalt}

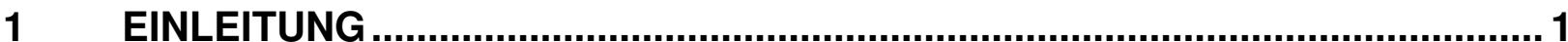

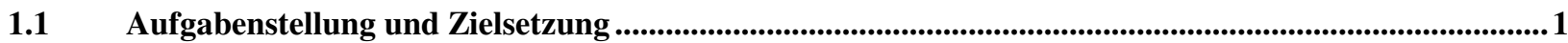

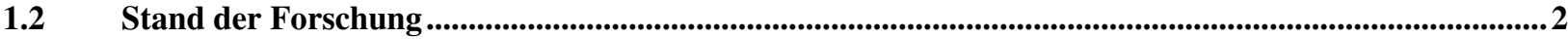

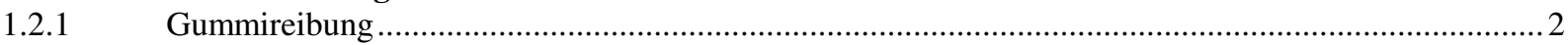

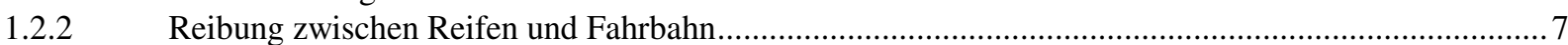

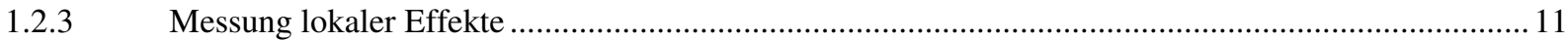

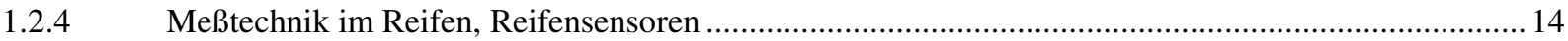

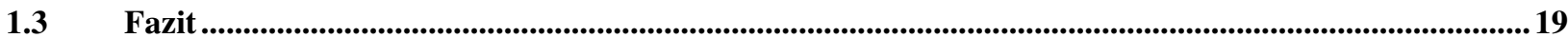

2 WERKZEUGE UND METHODIK DER VERSUCHE ...................................... 21

$2.1 \quad$ Prüfstand LINUS............................................................................................................................................... 21

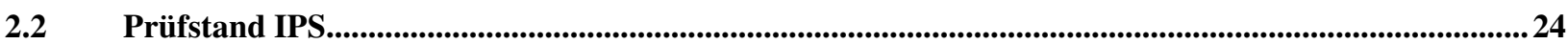

Gleitvorgänge, Sensorik in Reifen und Fahrbahn .....................................................................................3

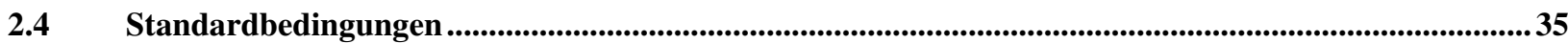

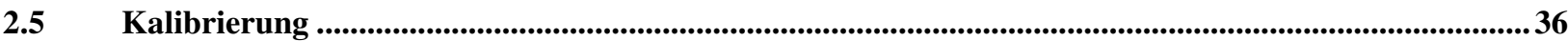

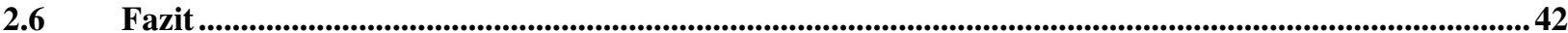

3 ERGEBNISSE ZUR LOKALEN KRAFTÜBERTRAGUNG............................. 44

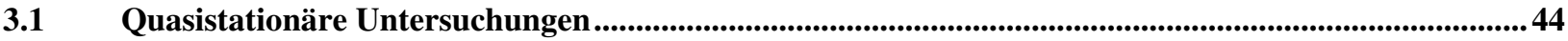

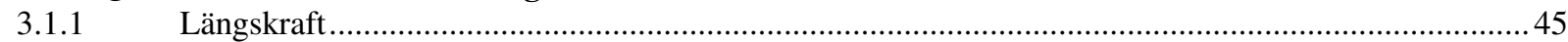

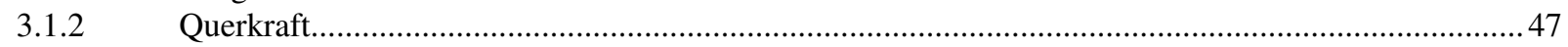

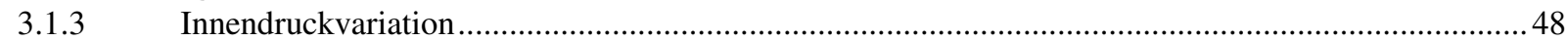

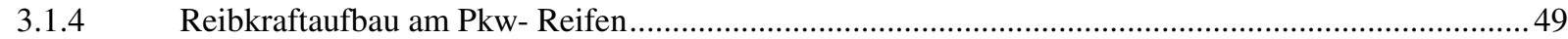

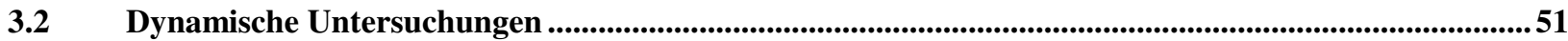

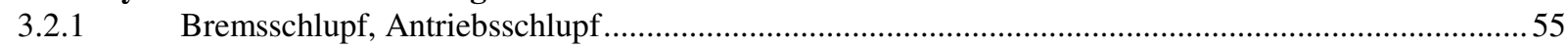

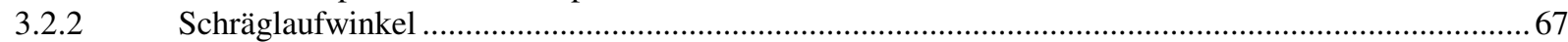

3.3 Erkenntnisse zur Reibwert- Schlupf Kurve .........................................................................................................70

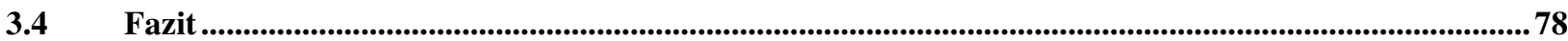




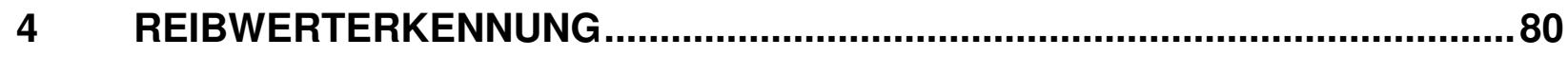

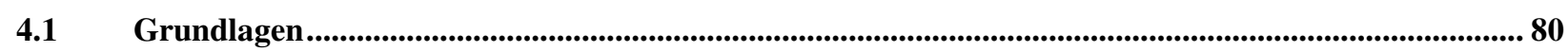

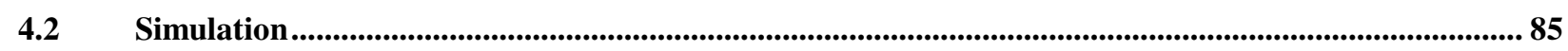

4.3 Ergebnisse mit der Reifensensorik .......................................................................................................... 91

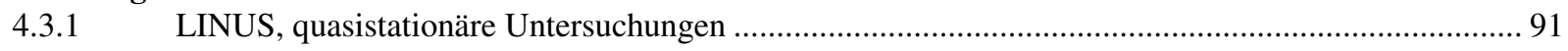

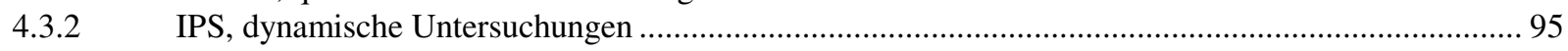

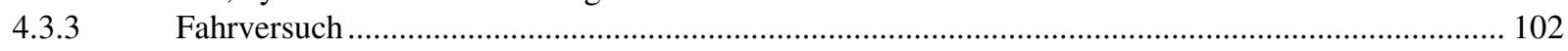

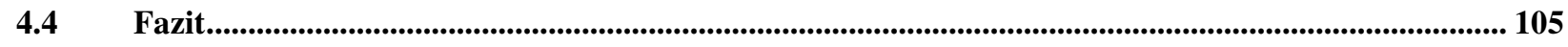

$5 \quad$ ABSCHLIEßENDE BETRACHTUNG UND AUSBLICK .................................106

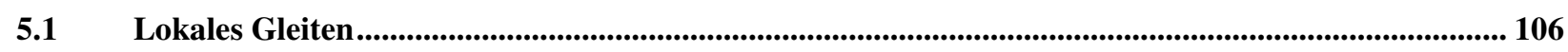

5.2 Reibwerterkennung ................................................................................................................................. 108

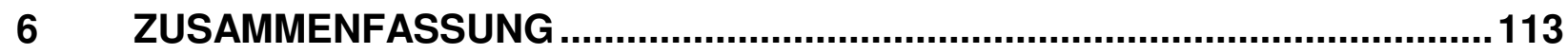

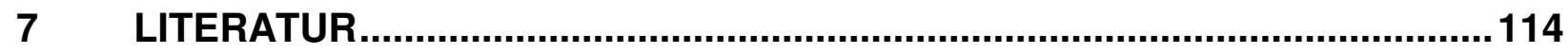

7.1 Studien und Diplomarbeiten ........................................................................................................................... 124

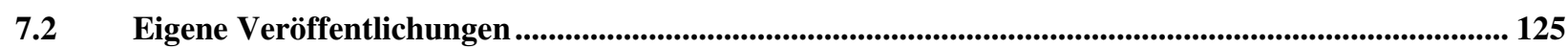

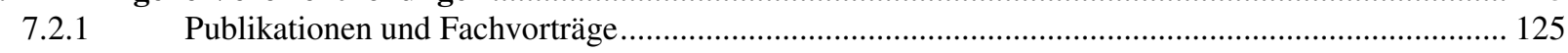

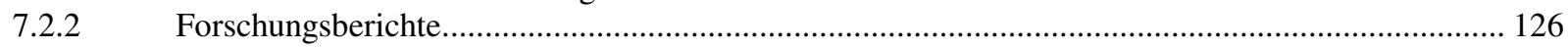




\section{Formelzeichen und Indizes}

\begin{tabular}{|c|c|c|}
\hline Symbol & Einheit & Bezeichnung \\
\hline $\mathrm{a}$ & {$[\mathrm{mm}]$} & Abstand \\
\hline $\mathrm{C}_{\mathrm{KFM}}$ & & Konstante zur Berechnung der Reibwertausnutzung \\
\hline $\mathrm{C}_{\mathrm{Kfx}}$ & [] & Konstante zur Berechnung der Kraft in x-Richtung \\
\hline $\mathrm{C}_{\mathrm{Kfy}}$ & [] & Konstante zur Berechnung der Kraft in y-Richtung \\
\hline $\mathrm{C}_{\mathrm{Ks}}$ & [] & Konstante zur Berechnung des Kennwertes für den Kraftschluß \\
\hline $\mathrm{C}_{\mathrm{KAV}}$ & [] & Konstante zur Berechnung des Kennwertes für den Kraftschluß \\
\hline $\mathrm{D}$ & [] & Verlustfaktor \\
\hline $\mathrm{d}$ & {$[\mathrm{mm}]$} & Abstand \\
\hline $\mathrm{E}$ & {$[\mathrm{kPa}]$} & Elastizitätsmodul \\
\hline $\mathrm{E}^{\prime}$ & {$[\mathrm{kPa}]$} & Speichermodul \\
\hline $\mathrm{E}^{\prime \prime}$ & {$[\mathrm{kPa}]$} & Verlustmodul \\
\hline $\mathrm{E}^{*}$ & {$[\mathrm{kPa}]$} & komplexer Modul \\
\hline $\mathrm{F}$ & {$[\mathrm{N}]$} & Kraft, Reibkraft \\
\hline $\mathrm{f}$ & [] & Reibzahl \\
\hline $\mathrm{F}_{\mathrm{a}}$ & {$[\mathrm{N}]$} & Adhäsionskraft \\
\hline$f_{a}$ & [] & Adhäsionsbeiwert \\
\hline$f_{B}$ & [] & Bremsbeiwert \\
\hline$F_{h}$ & {$[\mathrm{~N}]$} & Hysteresekraft \\
\hline $\mathrm{f}_{\mathrm{h}}$ & [] & Hysteresebeiwert \\
\hline $\mathrm{F}_{\mathrm{k}}$ & {$[\mathrm{N}]$} & Kohäsionskraft \\
\hline $\mathrm{F}_{\mathrm{N}}$ & {$[\mathrm{N}]$} & Normalkraft \\
\hline $\mathrm{F}_{\mathrm{R}}$ & {$[\mathrm{N}]$} & Reibkraft \\
\hline $\mathrm{F}_{\mathrm{S}}$ & {$[\mathrm{N}]$} & Seitenkraft \\
\hline $\mathrm{F}_{\mathrm{U}}$ & {$[\mathrm{N}]$} & Umfangskraft \\
\hline $\mathrm{F}_{\mathrm{v}}$ & {$[\mathrm{N}]$} & viskose Kraft \\
\hline $\mathrm{F}_{\mathrm{x}}$ & {$[\mathrm{N}]$} & Längskraft \\
\hline $\mathrm{F}_{\mathrm{y}}$ & {$[\mathrm{N}]$} & Querkraft \\
\hline $\mathrm{F}_{\mathrm{z}}$ & {$[\mathrm{N}]$} & Radlast \\
\hline
\end{tabular}




\begin{tabular}{|c|c|c|}
\hline $\mathrm{i}$ & [] & Laufvariable \\
\hline $\mathrm{K}_{\mathrm{fx}}$ & [] & Kennwert für die Profilelementverformung in $\mathrm{x}$-Richtung \\
\hline $\mathrm{K}_{\mathrm{fy}}$ & [] & Kennwert für die Profilelementverformung in y-Richtung \\
\hline KFM & [] & Kennwert zur Ermittlung der Reibwertausnutzung \\
\hline KS & [] & Kennwert zur Kraftschlußerkennung \\
\hline $\mathrm{K}_{\mathrm{AV}}$ & [] & Kennwert zur Kraftschlußerkennung \\
\hline Mx & {$[\mathrm{Nm}]$} & Moment um die x-Achse \\
\hline My & {$[\mathrm{Nm}]$} & Moment um die y-Achse \\
\hline $\mathrm{Mz}$ & {$[\mathrm{Nm}]$} & Moment um die z-Achse \\
\hline $\mathrm{PEV}_{\mathrm{x}}$ & {$[\mathrm{mm}]$} & Profilelementverformung in $\mathrm{x}$-Richtung \\
\hline $\mathrm{PEV}_{\mathrm{x}, \max }$ & {$[\mathrm{mm}]$} & Maximum der Profilelementverformung in x-Richtung \\
\hline $\mathrm{PEV}_{\mathrm{x}, \min }$ & {$[\mathrm{mm}]$} & Minimum der Profilelementverformung in x-Richtung \\
\hline $\mathrm{PEV}_{\mathrm{y}}$ & {$[\mathrm{mm}]$} & Profilelementverformung in y-Richtung \\
\hline $\mathrm{p}_{0}$ & {$\left[\mathrm{~N} / \mathrm{mm}^{2}\right]$} & Flächenpressung \\
\hline $\mathrm{p}_{\mathrm{i}}$ & [bar] & Reifeninnendruck \\
\hline$r_{\text {dyn }}$ & {$[\mathrm{m}]$} & Dynamischer Reifenhalbmesser \\
\hline s & {$[\%, \mathrm{~m}]$} & Reifenschlupf, Weg \\
\hline $\mathrm{S}_{\mathrm{A}}$ & {$[\%]$} & Antriebsschlupf \\
\hline $\mathrm{S}_{\mathrm{B}}$ & {$[\%]$} & Bremsschlupf \\
\hline $\mathrm{t}$ & {$[\mathrm{s}]$} & Zeit \\
\hline $\mathrm{T}$ & {$\left[{ }^{\circ} \mathrm{C}\right]$} & Temperatur \\
\hline $\mathrm{U}_{\mathrm{x}}$ & {$[\mathrm{V}]$} & Sensorsignalspannung x-Richtung \\
\hline $\mathrm{U}_{\mathrm{y}}$ & {$[\mathrm{V}]$} & Sensorsignalspannung y-Richtung \\
\hline $\mathrm{U}_{\mathrm{z}}$ & {$[\mathrm{V}]$} & Sensorsignalspannung z-Richtung \\
\hline $\mathrm{v}$ & {$[\mathrm{km} / \mathrm{h}]$} & Fahrgeschwindigkeit \\
\hline $\mathrm{v}_{\mathrm{R}}$ & {$[\mathrm{km} / \mathrm{h}]$} & Umfangsgeschwindigkeit des Rades \\
\hline $\mathrm{x}$ & {$[\mathrm{mm}]$} & Verschiebung in $\mathrm{x}$-Richtung \\
\hline $\mathrm{X}_{(\mathrm{PEV}, \min )}$ & {$[\mathrm{m}]$} & $\mathrm{x}$-Wert an der Stelle der maximalen Verformung in $\mathrm{x}$-Richtung \\
\hline $\mathrm{X}_{(\mathrm{PEV}, \mathrm{max})}$ & {$[\mathrm{m}]$} & $\mathrm{x}$-Wert an der Stelle der minimalen Verformung in $\mathrm{x}$-Richtung \\
\hline $\mathrm{y}$ & {$[\mathrm{mm}]$} & Verschiebung in y-Richtung \\
\hline $\mathrm{z}$ & {$[\mathrm{mm}]$} & Verschiebung in z-Richtung \\
\hline $\mathrm{Z}_{0}$ & {$[\mathrm{~mm}]$} & Grundabstand Sensor - Magnet \\
\hline$\tau$ & {$\left[\mathrm{N} / \mathrm{mm}^{2}\right]$} & mechanische Spannung \\
\hline
\end{tabular}




$\begin{array}{lll}\varepsilon & {[\mathrm{m}]} & \text { Dehnung } \\ \omega & {\left[\mathrm{s}^{-1}\right]} & \text { Kreisfrequenz } \\ \sigma_{(\mathrm{t})} & {\left[\mathrm{N} / \mathrm{mm}^{2}\right]} & \text { von der Zeit abhängige mechanische Spannung } \\ \delta & {[]} & \text { Verlustwinkel } \\ \alpha & \left.{ }^{\circ}\right] & \text { Schräglaufwinkel } \\ \gamma & \left.{ }^{\circ}\right] & \text { Sturzwinkel } \\ \mu & {[]} & \text { Kraftschlußbeiwert } \\ \mathrm{x}, \mathrm{y}, \mathrm{z} & & \text { Längs-, Quer- und Radialrichtung }\end{array}$




\section{Abkürzungen und Eigennamen}

Name

ABS

ASR

BASt

DFG

DMS

E-SBR

FDR

FEM

FIT

$f z d$

GaAs

IMES

IPS

LINUS

MPR

Pkw

PROMETHEUS

PVS

RPR

RW

SFB

$\mathrm{Si}$

SRM

SRT

$\mathrm{TP}$

WF

\section{Bezeichnung}

Antiblockiersystem

Antriebsschlupfregelung

Bundesanstalt für Straßenwesen in Bergisch Gladbach

Deutsche Forschungsgemeinschaft

Dehnungsmeßstreifen

Emulsion-Styrol-Butadien Rubber

Fahrdynamikregelung

Finite Elemente

Friction Indication Tread

Fachgebiet Fahrzeugtechnik der TU Darmstadt

Galliumarsenit

Intergrierte Mechatronische Systeme für den Maschinenbau

Innentrommelprüfstand der BASt

Reifenlinearprüfstand von $f z d$

Mittlere Profilrippe Versuchsreifen

Personenkraftwagen

Program for a European Traffic with Highest Efficiency and Unprecedented Safety

Profilelementverformungssensor

Rechte Profilrippe Versuchsreifen

Reibwert

Sonderforschungsbereich

Silizium

Stuttgarter Reibwertmesser

Skid Resistance Tester

Teilprojekt

Wasserfilmhöhe 


\section{Einleitung}

\subsection{Aufgabenstellung und Zielsetzung}

Die Kontaktstelle zwischen Reifen und Fahrbahn ist aufgrund ihrer Bedeutung für die Kraftübertragung vom Fahrzeug auf die Straße seit den Anfangszeiten der Kraftfahrzeugentwicklung Gegenstand zahlreicher experimenteller und theoretischer Untersuchungen. Die besondere Schwierigkeit der Forschungsarbeiten an dieser Stelle liegt in den speziellen Eigenschaften der beteiligten Werkstoffe begründet. Sowohl die Fahrbahnoberfläche mit ihren makroskopischen und mikroskopischen Eigenschaften als auch der mit der Fahrbahn in Kontakt stehende Reifengummi mit seinem viskoelastischen Verhalten bestimmen die Gesetzmäßigkeiten der Kraftübertragung in der Kontaktzone Reifen-Fahrbahn. In der Kette der kraftübertragenden Komponenten vom Schwerpunkt des Fahrzeugs bis hin zur Fahrbahn finden sich in dieser Kontaktzone die komplexesten Wirkmechanismen. Das Auftreten von Zwischenmedien kann die Verhältnisse zusätzlich beeinflussen und zu grundsätzlich anderen Wechselwirkungen führen.

Eine Vielzahl von Arbeiten zur Untersuchung der Kraftübertragung vom Reifen auf die Fahrbahn haben zu umfangreichen Erkenntnissen geführt, die geeignet sind, einzelne Aspekte und Wirkungsketten bei der Entstehung der Reibkräfte am Reifen zu erklären. Die außerordentliche Komplexität des Gesamtsystems hat es aber sehr erschwert, einen übergreifenden Ansatz zu entwickeln. Dieser sollte es ermöglichen, ausgehend von den Mikrorauhigkeiten der Fahrbahn über die chemischphysikalischen Eigenschaften des Gummis die lokalen Effekte in der Aufstandsfläche, die globale Struktur des Reifens und die miteinander in Wechselwirkung stehenden Einzelmechanismen in ihrem Gesamtzusammenhang zu beschreiben.

Ziel der vorliegenden Arbeit ist es, mit Hilfe von Sensoren im Reifen und in der Fahrbahn vertiefte Einblicke in die Vorgänge am kraftübertragenden Reifen zu erhalten, die einen Beitrag zum besseren Verständnis des Gesamtsystems Reifen- Fahrbahn liefern können.

Neben der Gewinnung grundlegender Erkenntnisse zum Reibkraftaufbau am Fahrzeugreifen haben in der Vergangenheit Bestrebungen stattgefunden, basierend auf dem Verständnis der den Reibprozeß beeinflussenden Parameter und der daraus resultierenden Effekte, Ansätze zu entwickeln, die mit Hilfe der Messung einzelner Schlüsselgrößen eine hinreichende Beschreibung des Gesamtsys- 
tems ermöglichen. Diese Arbeiten von Dieckmann [27], Görich [53] und Eichhorn [31] zielten nicht darauf ab, Reibwertmessungen zu vereinfachen. Ziel war vielmehr die Entwicklung von Systemen mit überschaubarer technischer Komplexität, die Informationen über das momentan vorhandene Reibwertpotential am fahrenden Fahrzeug mit hinreichender Auflösung und Genauigkeit bereitstellen können. Moderne fahrzeugtechnische Systeme zur Steigerung der Aktiven Sicherheit und noch vielmehr zukünftige Systeme könnten durch eine solche Information erheblich an Funktionspotential gewinnen.

Die in Darmstadt entwickelte Sensorik im Pkw-Reifen stellt eines dieser Systeme dar, denen Zukunftschancen für den Einsatz im Serien-Pkw eingeräumt werden können, wie Roth [100], [101] zeigen konnte. Der zweite Schwerpunkt der vorliegenden Arbeit ist daher die weitere Erforschung der reibwertabhängigen Phänomene, die mit dem Darmstädter Reifensensor erfaßt werden können. Dabei steht das bereits oben angesprochene Verständnis des Reibprozesses, insbesondere auf lokaler Ebene, im Vordergrund. Aus diesem Verständnis heraus sollen Ansätze abgeleitet werden, die unabhängig von der verwendeten Sensorik die aus unterschiedlichen Reibwerten resultierenden lokalen Effekte am Reifen erklären können. Von diesem Verständnis kann dann besonders die Entwicklung zukünftiger Reifensensoren profitieren, bei der eine seriennahe Daten- und Energieübertragung aus dem rotierenden Rad im Vordergrund steht.

\subsection{Stand der Forschung}

\subsubsection{Gummireibung}

Die Betrachtung der Reifen-Fahrbahn Reibung beginnt zweckmäßigerweise mit der Analyse der Reibpartner Gummi und Straßenoberfläche. Insbesondere die viskoelastischen Eigenschaften des Werkstoffes Gummi bestimmen hier zu einem wesentlichen Teil den Mechanismus der Reibung [85]. Zum besseren Verständnis kann zunächst die Struktur des rollenden Reifens vernachlässigt und das Verhalten des Gummiwerkstoffes in Form von Probenkörpern diskutiert werden.

Gummi ist ein polymerer Werkstoff, der bei seiner Verformung zum Teil elastisches und zum Teil viskoses Verhalten zeigt [56], [57]. Die Ursache dafür sind die langen, ineinander verschlungenen Molekülketten, die zum einen elastisch sind und gedehnt werden können und zum anderen relativ zueinander beweglich sind, also aneinander abgleiten können. Dies bedeutet, daß bei der Verformung eines Gummikörpers nur ein Teil der aufgewendeten Energie elastisch wieder zurückgewonnen, ein anderer Teil jedoch in Wärme umgewandelt wird [44]. Bild 1 zeigt den Zusammenhang 
zwischen Dehnung und Spannung einer Gummiprobe bei sinusförmiger Anregung mit konstanter Amplitude und Frequenz nach Gehmann [44]. Die viskoelastischen Eigenschaften des Gummis

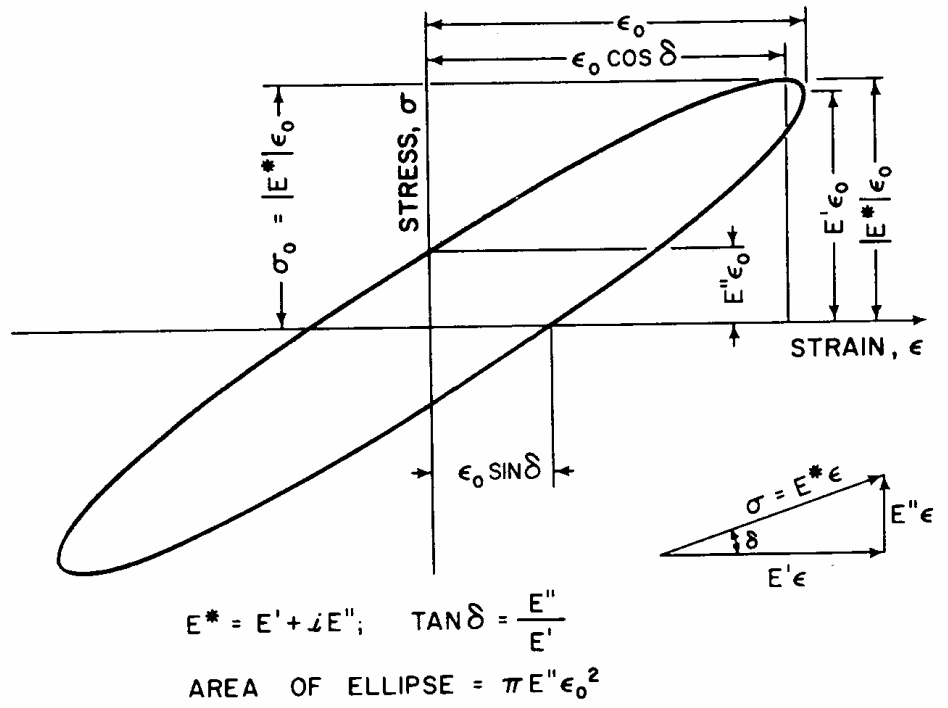

Bild 1: Gummieigenschaften, Zusammenhang zwischen Spannung und Dehnung nach Gehmann [44] lassen sich mit Hilfe solcher Versuche analysieren und in Kennwerte überführen.

Zwischen Dehnung und Spannung bildet sich eine Phasenverschiebung mit dem Winkel $\delta$ aus. Die auf die Gummiprobe wirkende Spannung setzt sich, wie oben beschrieben, aus einem elastischen Anteil E', dem sogenannten Dynamischen Modul, und aus einem Dämpfungsanteil E", dem Verlustmodul zusammen. Damit kann die resultie-

rende Spannung aus:

$$
\sigma(t)=E^{\prime} \cdot \varepsilon+E^{\prime \prime} \cdot \frac{1}{\omega}+\frac{d \varepsilon}{d t}
$$

berechnet werden. Das Verhältnis von Dynamischen Modul und Verlustmodul:

$$
D=\tan \delta=\frac{E^{\prime \prime}}{E^{\prime}}
$$

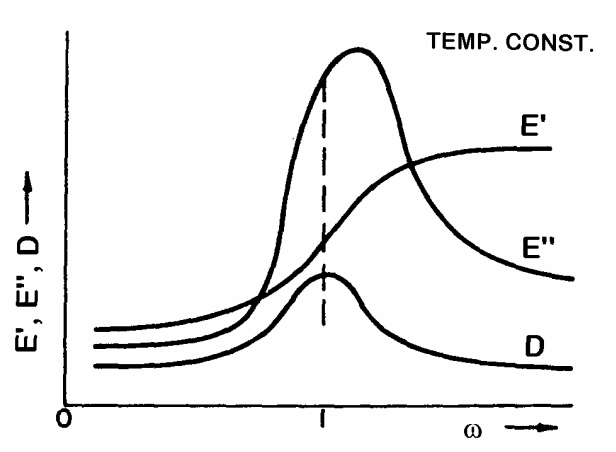

Bild 2: Speicher-, Verlustmodul und Verlusttangente nach Snowdon [110]

wird als Verlustfaktor bezeichnet. Es beschreibt den Anteil der inneren Dämpfung im Material bei äußerer Verformungsarbeit. Die charakteristischen Kenngrößen des Gummimaterials sind von der Anregungsfrequenz abhängig. Bild 2 zeigt diesen Zusammenhang, Snowdon [110].

Für eine konstante Temperatur zeigen die einzelnen Kenngrößen ein über der Anregungsfrequenz nichtlineares Verhalten, das für den Einfluß der Frequenz auf die Gummireibung eine große Rolle spielt. Der Übergang von dem Verformungsverhalten einer Gummiprobe zu seinen Reibungseigenschaften erfolgt über die Definition verschiedener Reibungsmechanismen. 


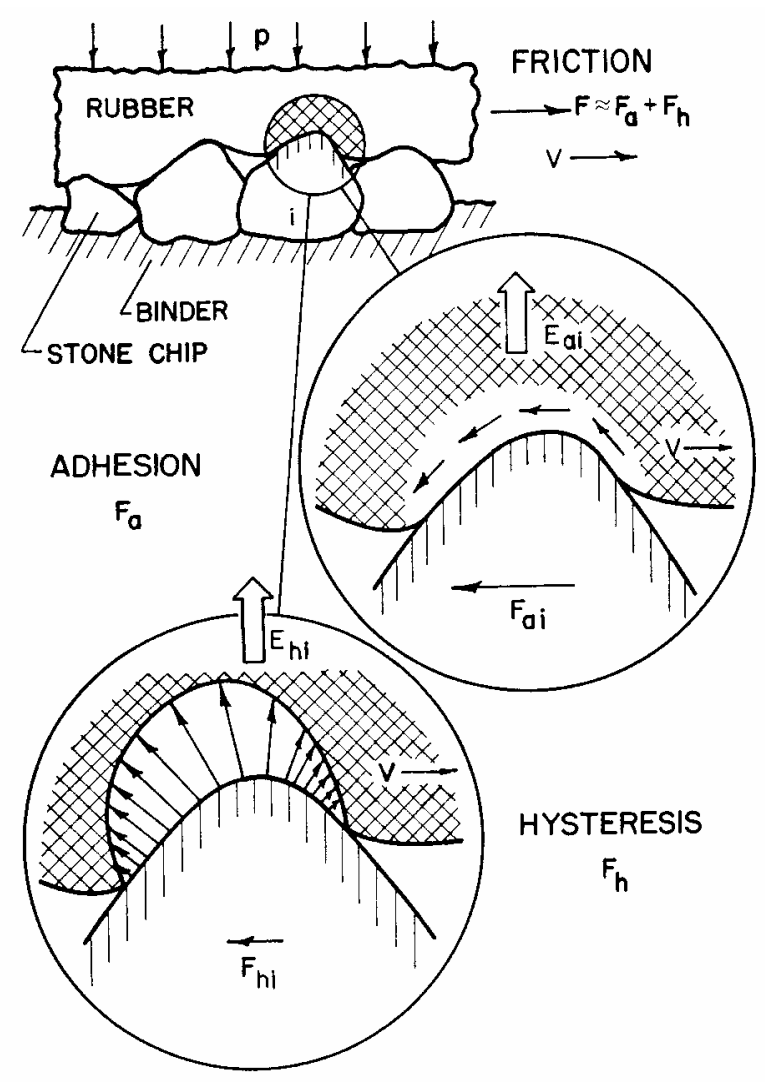

Bild 4: Modellvorstellung Gummireibungsmechanismen nach Kummer [79]
In Bild 4 sind die zwei wesentlichen Reibungsmechanismen der Gummireibung nach einem Modell von Kummer [79] dargestellt. Die Hauptkomponenten der Reibung sind die Adhäsionsreibung und die Hysteresereibung. Adhäsion bezeichnet die Ausbildung von Bindungskräften zwischen Gummi und Reibpartner auf molekularer Ebene, Hysterese entsteht bei der verlustbehafteten Verformung des Gummis auf einer rauhen Oberfläche. Beide Mechanismen werden durch eine Bewegung des Gummis relativ zur Reiboberfläche angeregt. Dabei sind unterschiedliche Gleitgeschwindigkeiten zur Anregung der jeweiligen Reibungskomponente erforderlich. Aus der Tatsache, daß es sich bei der Reibung von Gummi auf einer Oberfläche um einen verlustbehafteten Vorgang handelt und die

Gleitgeschwindigkeit die Anregungsfrequenz dieses Vorgangs bestimmt, ergibt sich die Analogie $\mathrm{zu}$ den oben beschriebenen Gummieigenschaften bei Verformung unter sinusförmiger Amplitude. Die Abhängigkeit der Gummieigenschaften von der Anregungsfrequenz und damit des Reibungsverhaltens von der Gleitgeschwindigkeit zeigt Bild 3. Die beiden Hauptkomponenten der Reibung zeigen ihre maximale Ausprägung

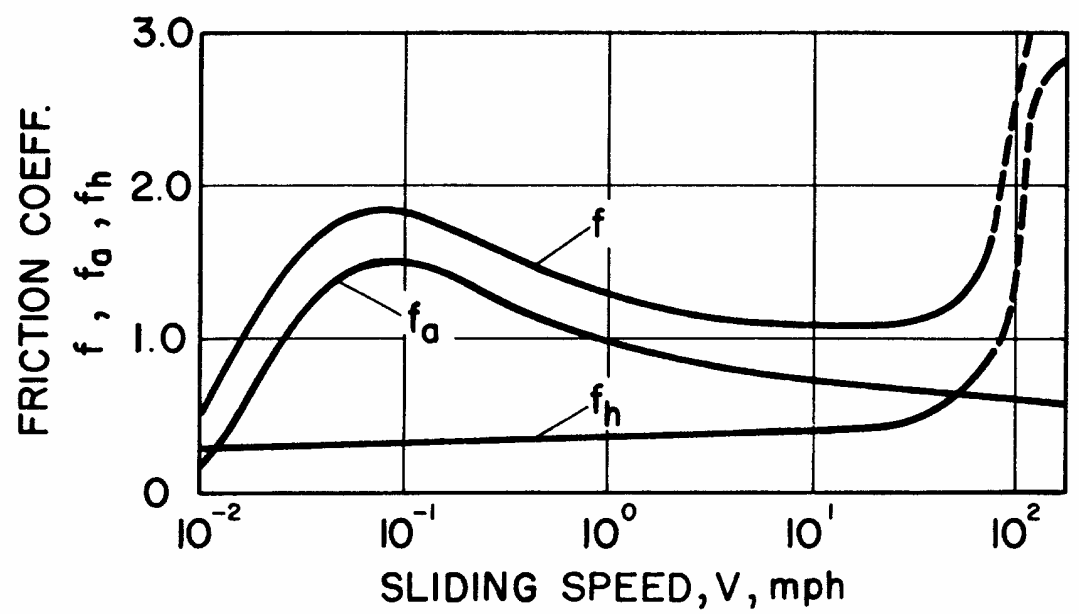

Bild 3: Adhäsion $f_{a}$, Hysterese $f_{h}$ und Gesamtreibkraft $f$ auf trockener Fahrbahn nach Kummer [84] bei unterschiedlichen Gleitgeschwindigkeiten. In der Summe entsteht das charakteristische Gesamtverhalten der Reibung von Gummi in Abhängigkeit von der Gleitgeschwindigkeit. Der starke Anstieg der Hysteresekomponente wurde bislang experimentell nur bei landenden Flugzeugen beobachtet [128] und kann daher 
für die Reibung an Pkw- Reifen außer acht gelassen werden. Der Ansatz von Kummer und Meyer wurde von Rieger [99], Schmallnach [106], [107] und Geyer [49] aufgegriffen und vertieft. Die Verhältnisse der Reibung von Gummi auf inhomogenen Oberflächen wie Eis wurde von Wilkingson [122] untersucht. Ein neuerer Ansatz von Persson [93] vereinigt die Mechanismen von Adhäsion und Hysterese, in dem Adhäsionseffekte auf nanoskalige Rauhigkeiten zurückgeführt werden, die bei sehr niedrigen Gleitgeschwindigkeiten hystereseähnliche Reibkräfte erzeugen.

Insgesamt setzt sich nach der vereinheitlichten Reibungstheorie nach Kummer die Reibungskraft an einer Gummiprobe aus den Komponenten:

$$
F=F_{\text {Adhüsion }}+F_{\text {Hysterese }}+F_{\text {Kohäsion }}+F_{\text {Viskose }}=F_{a}+F_{h}+F_{k}+F_{v}
$$

zusammen. Adhäsion und Hysterese werden ergänzt durch die Kohäsionsreibung, die durch den Energieverbrauch beim Verschleiß von Gummi entsteht, und durch die viskose Reibung in Flüssigkeitsschichten. Alle diese Komponenten sind unterschiedliche Verbrauchsarten der gleichen Energie und bilden zusammen die Gummireibung. Neben der Gleitgeschwindigkeit, die eine bedeutende Rolle spielt, zeigen noch andere Umgebungsparameter Einflüsse auf die Gummireibung, Bild 5.
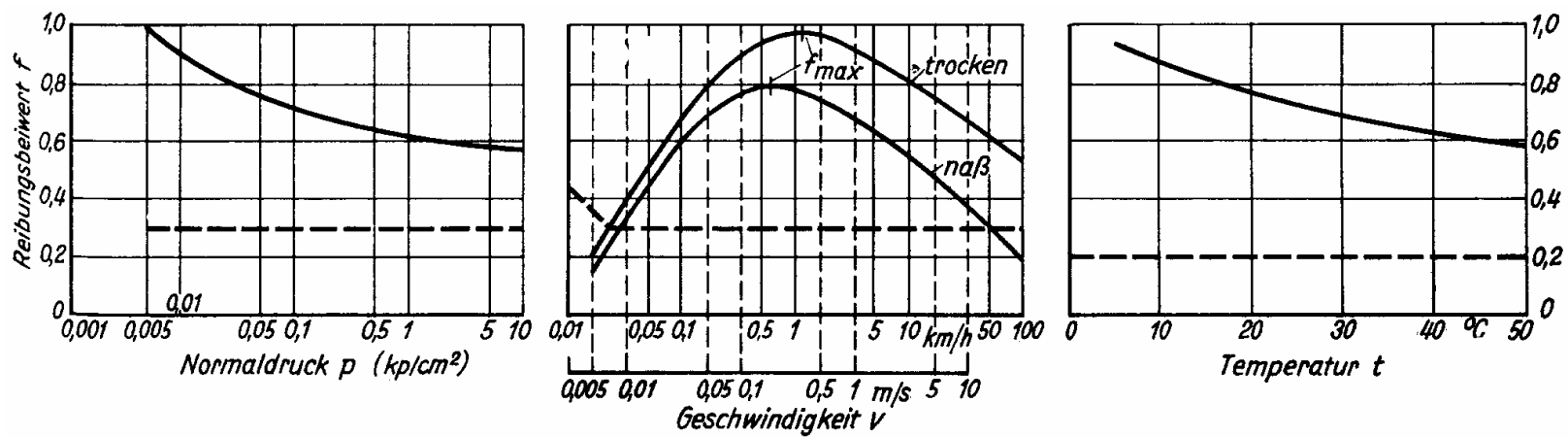

Bild 5: Vereinheitlichte Gummireibungstheorie nach Meyer und Kummer [84], Vergleich von Coulomb'scher-(----) und Gummi- Reibung ( $\longrightarrow$

So sinken z. B. die Reibbeiwerte einer Gummiprobe mit steigender Flächenpressung und mit steigender Temperatur. Die Gummireibung unterscheidet sich durch dieses Verhalten wesentlich von der Coulomb'schen Reibung, bei der diese Größen keinen Einfluß haben.

Die prinzipielle Frequenzabhängigkeit und die Analogie des Reibverhaltens von Gummiproben mit deren Verformungsverhalten kann dazu genutzt werden, die Reibungseigenschaften von Gummimischungen mit Hilfe von Deformationsversuchen vorherzusagen [110]. Dadurch können aufwendige Versuche mit Reifenmustern reduziert werden. Zusätzlich wird dabei ausgenutzt, daß Versuche bei 
höherer Frequenz durch Untersuchungen bei niedrigerer Frequenz und abgesenkter Temperatur abgebildet werden können, Williams et. al. [124]. Man erhält aus der Ermittlung des Verlustfaktors $\tan \delta$ bei konstanter Frequenz und Amplitude, aber unterschiedlicher Temperatur, die sogenannte „Meisterkurve“ der jeweiligen Gummimischung. Bild 6 enthält eine solche Kurve mit Erläuterungen der wesentlichen Zusammenhänge, Huinink [63].

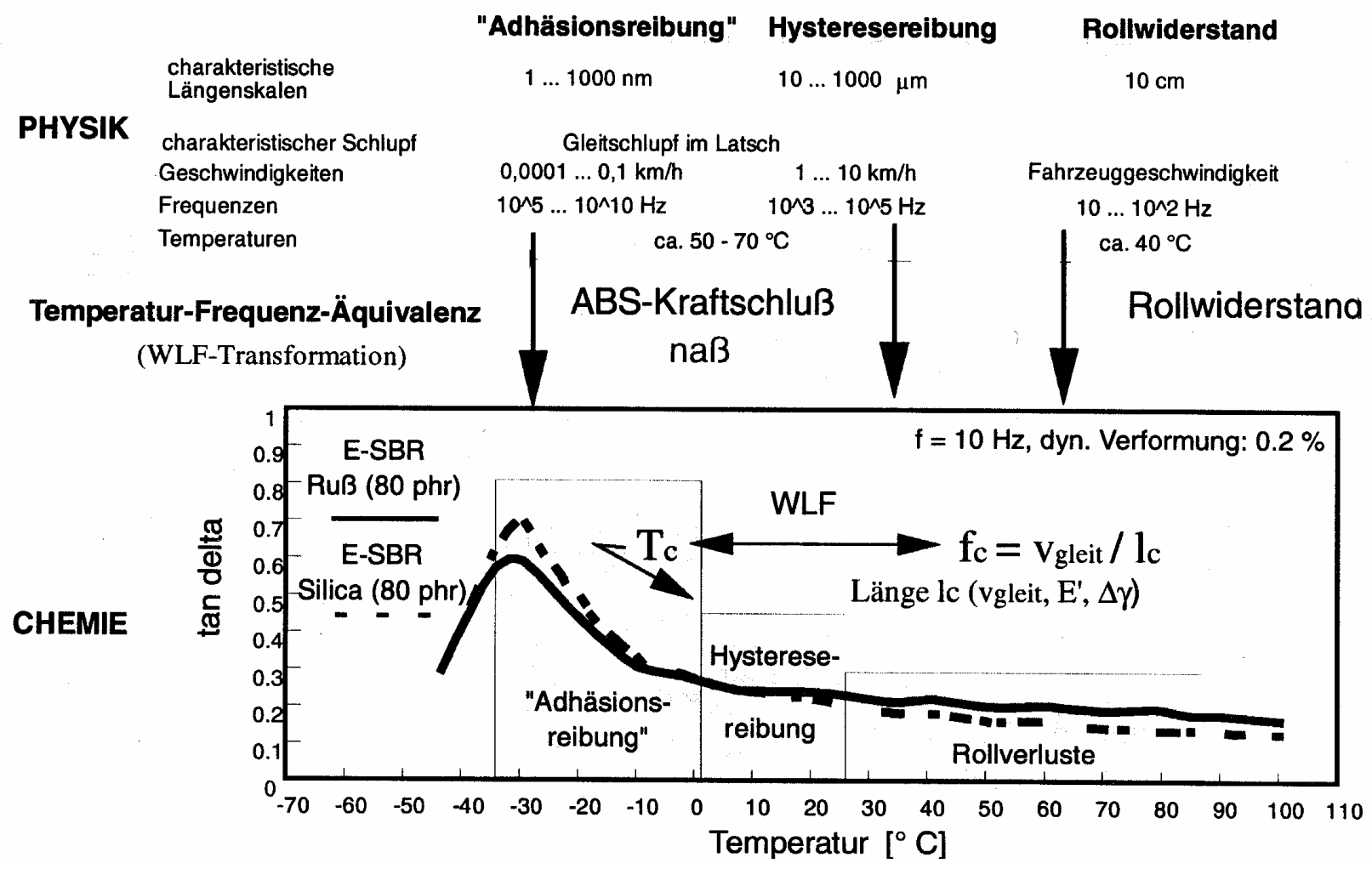

Bild 6: Vorhersagemodell zur Beurteilung der Eigenschaften von Gummiproben nach Huinink et al. [63] .E-SBR: Emulsion-Styrol-Butadien Rubber, silica- bzw. rußverstärkter Gummi mit $80 \mathrm{phr}$ (parts per hundred $\approx \%$ ) im Vergleich. Charakteristische Länge lc, charakt. Frequenz fc, Gleitgeschw.: vgleit.

Im niedrigen Temperaturbereich, der hohen Anregungsfrequenzen äquivalent ist, bedeuten hohe Werte für tan $\delta$ ein günstiges Adhäsionsreibungsniveau und damit gute Werte für das Reibverhalten. Im hohen Temperaturbereich, der niederfrequenten Anregungen entspricht, werden niedrige Werte für $\tan \delta$ angestrebt, die hier einen günstigen Rollwiderstand versprechen. In der Darstellung sind die Meisterkurven für zwei unterschiedliche Gummimischungen aufgetragen. Ein konventioneller rußverstärkter Gummi wird mit einem silicaverstärktem Gummi verglichen, der sowohl für die Naßreibung als auch für den Rollwiderstand bessere Werte liefert. In den jeweiligen Frequenzbzw. Temperaturbereichen zeigen sich die entsprechenden Unterschiede bereits am $\tan \delta$. Die Verbreitung Silica verstärkter Gummimischungen nimmt aufgrund der gezeigten Vorteile stark zu. 


\subsubsection{Reibung zwischen Reifen und Fahrbahn}

Die prinzipiellen Charakteristika der Gummireibung lassen sich auf den rollenden Pkw-Reifen übertragen. Dabei werden allerdings die spezifischen Randbedingungen eines unter Innendruck stehenden rotationssymmetrischen Körpers, der unter einer Radlast abgeplattet wird, überlagert. Die eigentlichen Phänomene der Gummireibung laufen in einer verhältnismäßig kleinen Kontaktzone zwischen Reifen und Straße ab, die sich unter dem Einfluß der globalen Reifenstruktur ausbildet. Dabei entstehen Schubspannungen, die schon am freirollenden Rad zu Verformungen im Laufstreifengummi führen und den Kraftschluß lokal beanspruchen [101]. Die Übertragung äußerer Kräfte führt zu einer Überlagerung von zusätzlichen lokalen Spannungen und Verformungen. In Bild 7 ist das sog. „Borstenmodell“ des Reifen dargestellt, in dem der Laufstreifengummi, bestehend aus Profilelementen, unter den wirkenden lokalen Kräften Verformungen zeigt, die im Modell durch die Verformung der Borsten symbolisiert werden.

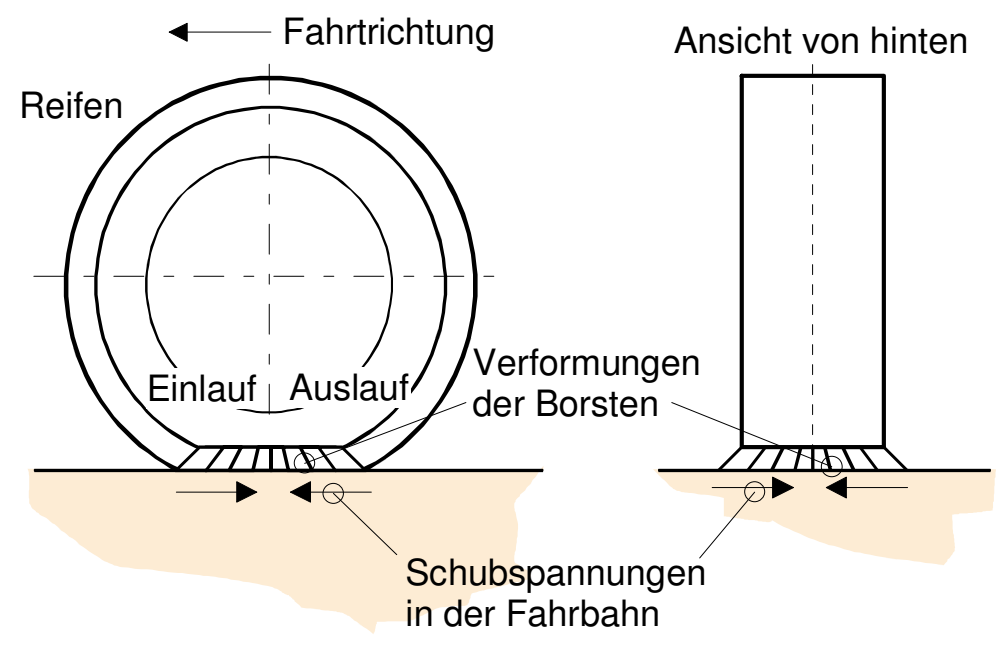

Bild 7: Borstenmodell des abgeplatteten Pkw- Reifens
Die Abplattung des Reifens bewirkt in der Kontaktzone, dem Reifenlatsch, sowohl in der Seitenansicht als auch in der Ansicht von hinten nach außen gerichtete Verformungen, wie sie in etwa auch beim Andrücken einer Bürste entstehen. Die damit einher gehenden reibwertbeanspruchenden Schubspannungen, die in der Fahrbahn nach innen gerichtet sind, müssen bei der Be-

trachtung der Reibverhältnisse in der Aufstandsfläche berücksichtigt werden und bilden einen wesentlichen Unterschied zu den im vorangegangenen Kapitel beschriebenen Verhältnissen an Gummiproben.

Die für das Entstehen einer Reibkraft erforderliche Gleitgeschwindigkeit wird am Reifen durch den Reifenschlupf erzeugt, der nach der Formel:

$$
s_{A}=\frac{v_{R}-v}{v_{R}}
$$

für den Antriebsfall und: 


$$
S_{B}=\frac{v-v_{R}}{v}
$$

für den Bremsfall definiert ist.

Entsprechend dieser Definition handelt es sich beim Schlupf um eine Gleitgeschwindigkeit, die im Bremsfall auf die Fahrgeschwindigkeit bezogen ist. Die effektive Gleitgeschwindigkeit steigt in beiden Fällen bei konstantem Schlupf und zunehmender Fahrgeschwindigkeit. Der Reibwert zwischen Reifen und Straße wird dimensionslos mit:

$$
\mu=\frac{F_{R}}{F_{N}}
$$

berechnet. Man gelangt so zur gebräuchlichen Darstellung der Reibwert-Schlupf bzw. $\mu$-s Kurve.

Ein weiterer Unterschied $\mathrm{zu}$ der an Gummiproben ermittelten Gleitgeschwindigkeit zeigt sich beim Schlupf in dem sog. Deformationsschlupf, der auf rein elastische Verformungen im Laufstreifengummi zurückzuführen ist. Diese elastischen Deformationsanteile werden bei der Ermittlung des Gesamtschlupfs am Reifen miterfaßt und sind nur schwer von den tatsächlichen Gleitanteilen zu
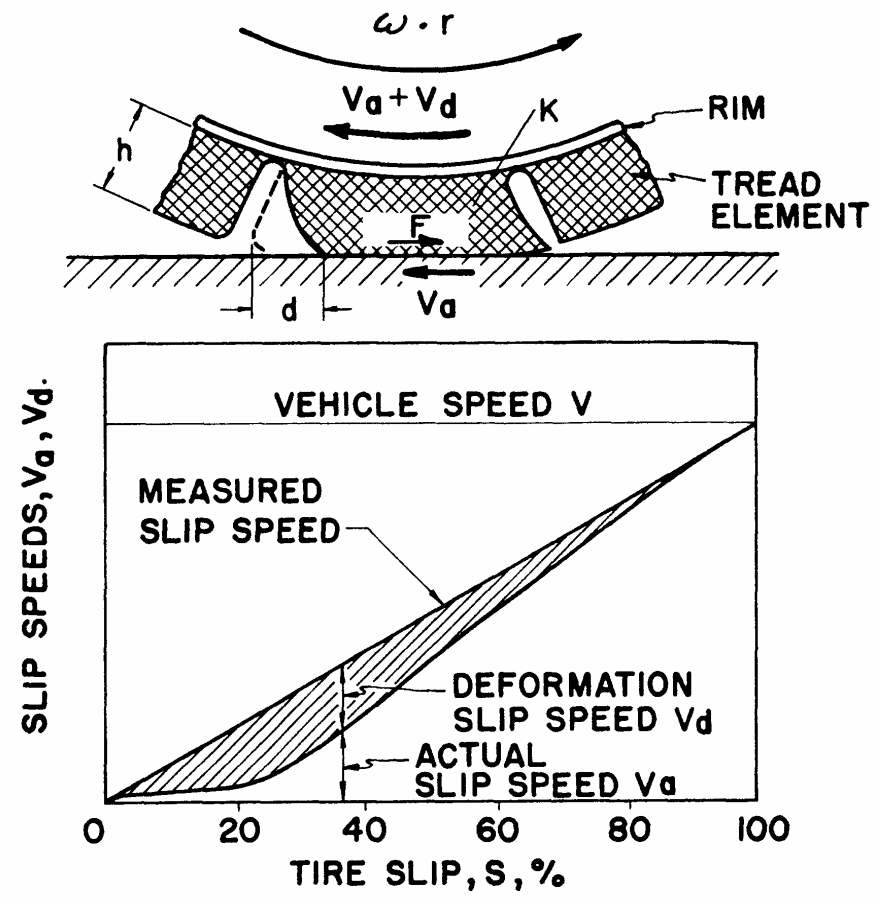
trennen. Bild 8 zeigt ein Modell zur Bild 8: Zusammenhang zwischen Deformationsschlupf und Aufteilung von Deformations- und Gleitschlupf nach Kummer [79] Gleitschlupf am Reifen nach Kummer [79].

Für kleine Schlupfwerte dominiert der Deformationsanteil, der ab einem bestimmten Wert, der maximal möglichen Deformation im Laufstreifen, nicht mehr steigt. Dementsprechend sinkt mit weiter zunehmendem Gesamtschlupf der Anteil des Deformationsschlupfs, bis bei einem Wert von 100\% für den Gesamtschlupf, gleichbedeutend mit einem blockierten Rad, der Deformationsanteil Null wird und reines Gleiten vorliegt. 
Dieser Zusammenhang führt in der Darstellung der Reibwert-Schlupf-Kurve zur relativ steilen Anfangssteigung, bei der überwiegend Deformationsschlupf vorliegt.

Neben der Anfangssteigung sind die Höhe des Reibwertmaximums und dessen Lage wichtige Charakteristika der Reibwert-Schlupf Kurve. In Bild 9 ist eine typische $\mu$-s Kurve, die im Rahmen dieser Arbeit aufgenommen wurde, mit den entsprechenden Kenngrößen dargestellt.

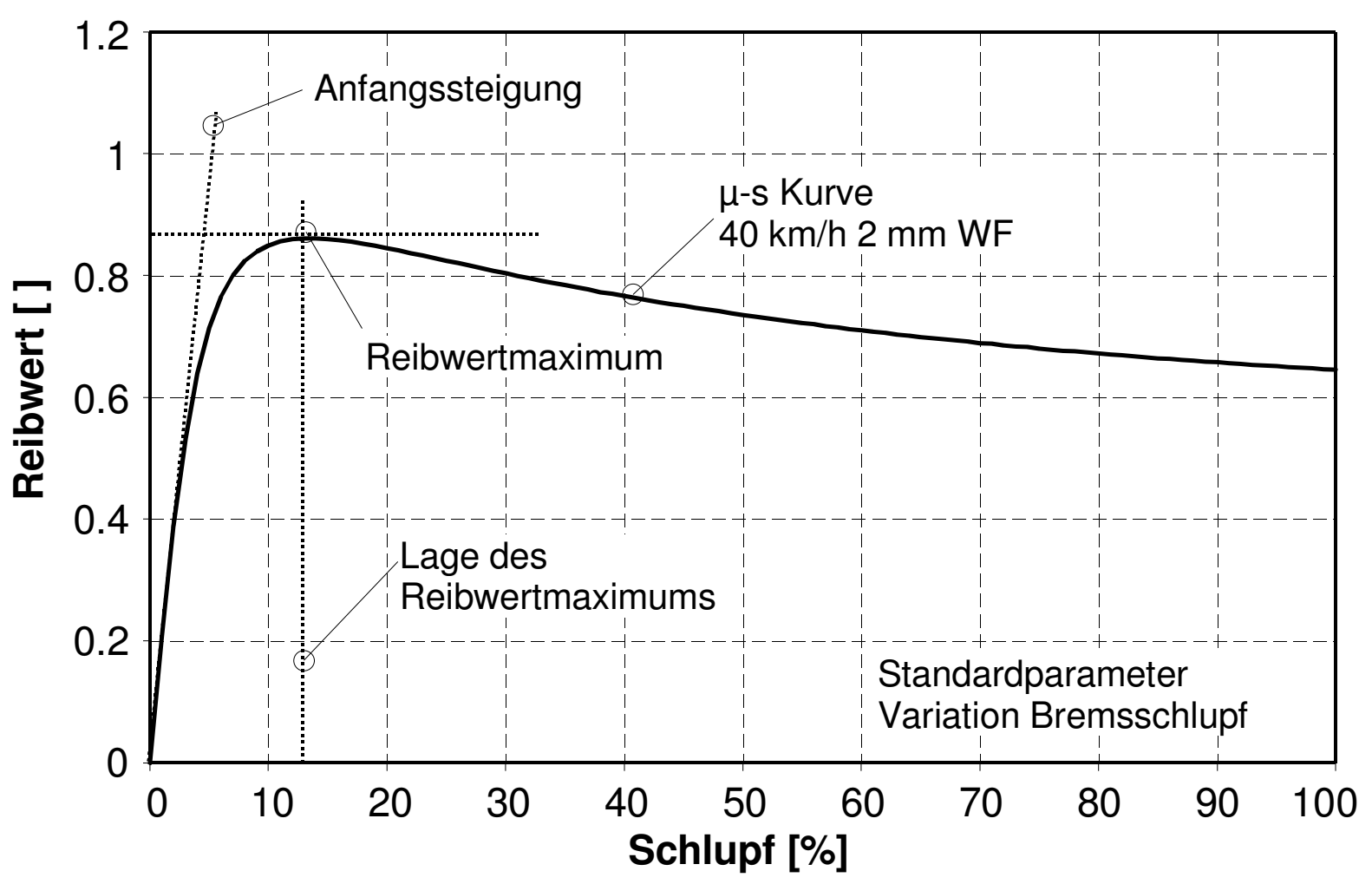

Bild 9: Kenngrößen der Reibwert-Schlupf-Kurve (Standardparameter siehe Kapitel 2.4)

Die Variation von Betriebsbedingungen kann zu einer Veränderung der Reibwert-Schlupf-Kurve führen. Insbesondere das Auftreten eines Zwischenmediums, im häufigsten Falle Wasser, führt zu einer Absenkung des Reibwertniveaus und unter Umständen auch zu einer Veränderung der übrigen charakteristischen Kenngrößen. Diese und andere Einflüsse auf die Reibwert-Schlupf-Kurve konnten in zahlreichen Untersuchungen zum Thema der Übertragung von Kräften zwischen Reifen und Fahrbahn nachgewiesen werden, z.B.: Bachmann [2], [4], Eichhorn [29], [30], [31], Roth [100], [101], Gerresheim [47], [48], Rado [95], Gauß [43], Grandel [55], Kelley [70], Krempel [76] und insbesondere Paceijka [90], [91], der ein Modell zur mathematischen Beschreibung des charakteristischen Verlaufs von Reibwert-Schlupf-Kurven entwickelte. 

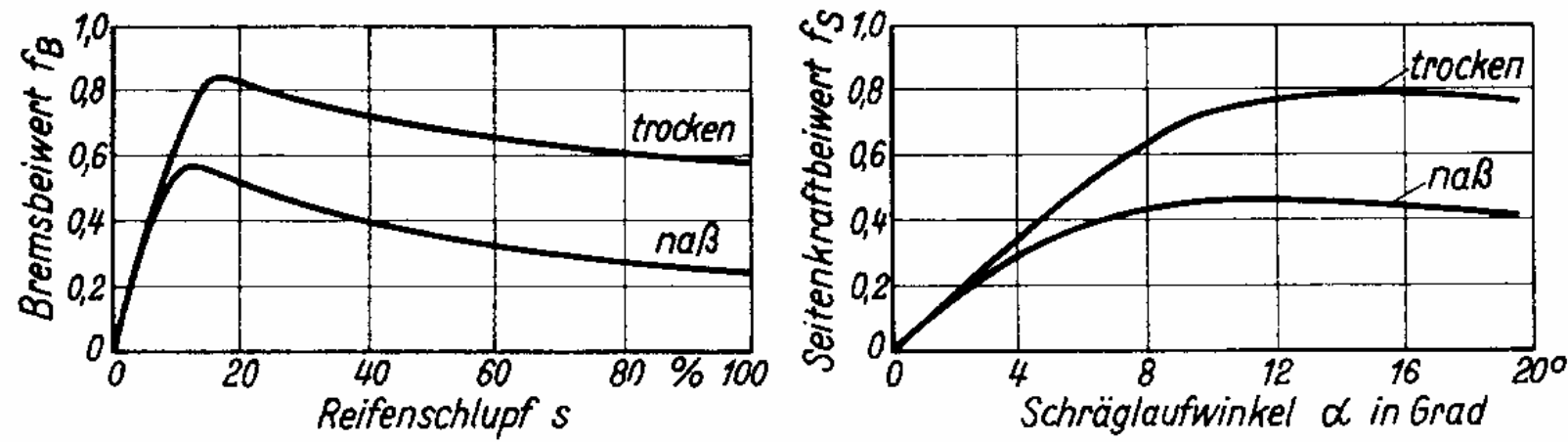

Bild 10: Prinzipieller Verlauf von Reibwert-Schlupf und Schräglaufwinkel-Seitenkraftbeiwert-Kurven nach Kummer und Meyer [77]

Bild 10 enthält die Reibwert- Schlupf Kurven eines Reifens unter trockenen und nassen Bedingungen nach Kummer und Meyer [77]. Die Absenkung des Reibwertniveaus durch das Wasser ist deutlich zu erkennen. Eine Veränderung der Anfangssteigung tritt jedoch nicht auf. Die Lage des Reibwertmaximums verschiebt sich für den nassen Fahrbahnzustand sogar hin zu niedrigeren Schlupfwerten. Diese Effekte wurden auch von Bachmann [4] gemessen und widersprechen den Annahmen von Dieckmann [27], der einen Zusammenhang zwischen fallendem Reibwertmaximum und flacher werdender Anfangssteigung zur Reibwerterkennung nutzen wollte. Im weiteren Verlauf dieser Arbeit wird dazu noch Stellung genommen (Kapitel 3.3).

In einer Übersicht ist in Bild 11 der Einfluß wesentlicher Betriebsparameter auf das Reibwertmaximum der $\mu$-s Kurve für trockenen und nassen Fahrbahnzustand schematisch dargestellt.

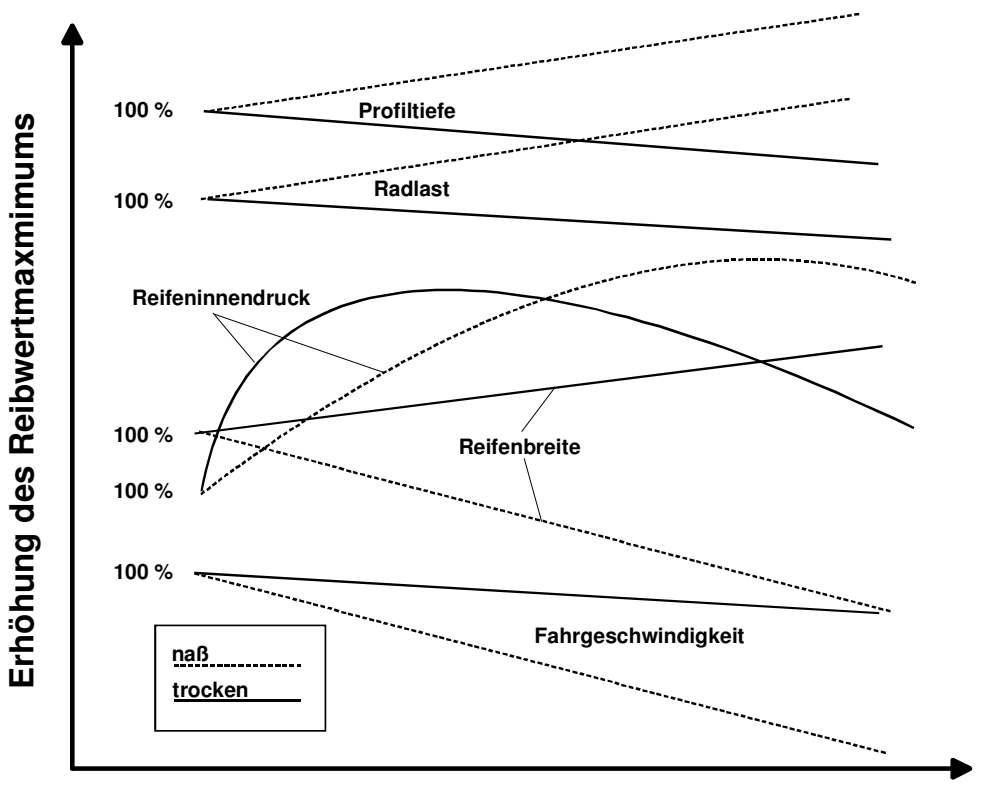

Erhöhung des jeweiligen Parameters

Bild 11: Einfluß verschiedener Parameter auf den Maximalreibwert zwischen Reifen und Straße

Die Darstellung berücksichtigt eigene Messungen [34], [35], [36], [37], und vereinfacht die Verhältnisse zum Teil stark. Besonders bei Nässe sind erhebliche Unterschiede zwischen kleinen und großen Wasserfilmhöhen, bei denen Aquaplaning auftreten kann, zu verzeichnen. Die Komplexität der Zusammenhänge wird insbesondere beim Einfluß des Reifeninnendrucks deutlich. Hohe Drük- 
ke sind bei Trockenheit entsprechend der Gummireibungstheorie dem Reibwert abträglich, während sie bei Nässe die Wasserverdrängung fördern und damit die Reibung begünstigen. Zu niedriger Reifeninnendruck kann jedoch auch auf trockener Fahrbahn nachteilig sein, wenn die dadurch verstärkten abplattungsbedingten Schubspannungen zuviel des vorhandenen Reibwerts in Anspruch nehmen. Bei Nässe führt ein zu hoher Innendruck zu einer Verkürzung des Reifenlatschs, was ein Eindringen des Wasserkeils und Aufschwimmen des Reifens begünstigt. Steigende Fahrgeschwindigkeit führt zu einem Absinken der Maximalreibwerte aufgrund der steigenden Gleitgeschwindigkeiten bzw. der kürzeren Verweilzeit der Profilelemente im Latsch, auf Nässe noch verstärkt durch hydrodynamische Effekte des Aufschwimmens. Breitere Reifen begünstigen das Aufschwimmen ebenso, während bei Trockenheit ihre niedrigere Flächenpressung und größere Steifigkeit die Reibung erhöhen. Ähnlich gestaltet sich die Situation bei niedriger Profilhöhe, die bei Nässe jedoch fatale Folgen haben kann. Höhere Radlasten wiederum erschweren das Aufschwimmen bei Nässe, führen auf trockener Fahrbahn jedoch zu höheren Flächenpressungen und größeren abplattungsbedingten Schubspannungen mit den entsprechenden negativen Konsequenzen für den Reibwert.

Insgesamt sind zur Reibung zwischen Reifen und Fahrbahn eine Vielzahl von Arbeiten publiziert worden. Dabei standen zum einen die Beurteilung der Griffigkeit von Fahrbahnoberflächen im Vordergrund, wie bei Brown [19], FGSV [32], Gengenbach [45], [46], Gillespie [50], Henry [62], Huschek [65], Kraemer [74], Litzka [81], Saito [105] und Wehner [121]. Daneben finden sich entsprechende Arbeiten mit dem Schwerpunkt der Reifeneigenschaften und der Betriebsparameter im Zusammenhang mit dem Reibwert von Reifen, z.B. Breuer [17], [18], Eichhorn[29], [30], [31], Haken [60], Kalender [68], Laermann [80], Sacia [104], Wang [117], Williams [123] und Yager [125]. Bei vielen dieser Arbeiten wurden sowohl die Kraftübertragung in Längsrichtung als auch die Übertragung von Seitenkräften untersucht. Hier konnten insbesondere in den Arbeiten von Weber [118], [119], [120] Analogien nachgewiesen werden, die es gestatten, vom Reibwert in Längsrichtung auf das Verhalten eines Reifens unter Schräglaufwinkeln zu schließen.

Die Aufzählung aller Quellen würde den Rahmen dieser Arbeit bei weitem überschreiten. Eine sehr gute Übersicht bieten die Sammlungen von Bachmann [3] und Clark [87].

\subsubsection{Messung lokaler Effekte}

Bereits früh fanden fahrbahnseitige Untersuchungen der in der Aufstandsfläche von rollenden PkwReifen ablaufenden Vorgänge statt. Martin stellte in [83] ein Bodendruckprüfgerät vor, mit dem die lokalen Kräfte im Reifenlatsch von Pkw-Reifen gemessen werden konnten. Eine Vielzahl von Au- 
toren hat sich seither mit den lokalen Kräften in der Aufstandsfläche von Fahrzeugreifen beschäftigt. Dabei wurden oft in die Fahrbahn eingelassene Kraftaufnehmer eingesetzt. Wichtiges Hilfsmittel war in der Vergangenheit der von Gough [52] vorgestellte Apparat, der die Kräfte auf in der Fahrbahn eingelassenen schmalen Balken in drei Koordinatenrichtungen messen konnte. Dabei wurden die lokalen Kräfte jeweils über die Fläche des Meßbalkens integriert. Kraft untersuchte erstmals in [75] den Einfluß von Betriebsparametern wie Radlast und Reifeninnendruck auf die Schubspannungen im Reifenlatsch. Bode [11] untersuchte darüber hinaus den Einfluß von Schräglauf und Bremsschlupf.

Neben der Messung von Kräften fanden auch Messungen der Gleitbewegungen in der Aufstandsfläche statt. Dabei wurden optische Verfahren zusammen mit Glasfahrbahnen eingesetzt oder Wegaufnehmer verwendet, die in der Fahrbahn integriert waren. Diese ähneln sich in ihrer Konstruktion. Sie bestehen aus einem Aufnehmer, in der Regel einer Nadel, die möglichst kraftfrei den Bewegungen der Gummielemente auf der Fahrbahn folgen kann. Dazu muß an der Stelle des Aufnehmers eine Öffnung in der Fahrbahnoberfläche vorhanden sein, die den maximal zulässigen Gleitweg bestimmt. Einen besonders aufwendigen Aufnehmer verwendete Gerresheim [48], dargestellt

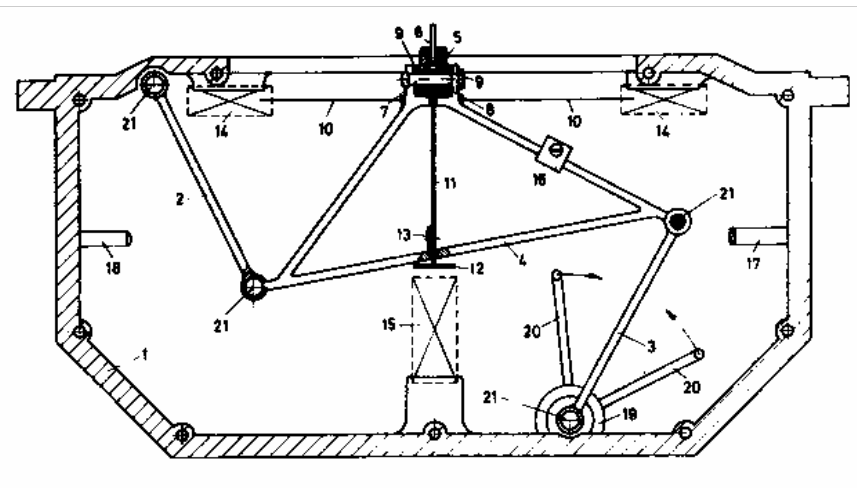

Bild 12: Vorrichtung zur Erfassung lokaler Gleitbewegungen auf einer Stahltrommel nach Gerresheim [47] in Bild 12. Dieser Aufnehmer wurde in einer Stahtrommel eingesetzt und verfügt deshalb über einen Mechanismus zum Ausgleich der wirkenden Fliehkräfte. Daneben wurde ein aufwendiger Rückstellmechanismus eingesetzt, der den Aufnehmer nach jeder Überrollung wieder in seine Ausgangslage zurückzieht, ohne Rückstellkräfte während der Messung zu verursachen, wie dies z.B. bei einer einfache Federkonstruktion der Fall wäre. Mit

dieser Vorrichtung konnte Gerresheim die lokalen Gleitbewegungen von schräglaufenden und gebremsten Reifen auf einer Stahltrommel untersuchen und Schlußfolgerungen für eine möglichst effektive Reifenkonstruktion ableiten [47], [48].

Bild 13 enthält das Ergebnis einer solchen Messung und die unter gleichen Bedingungen mit Hilfe eines kraftmessenden Elements ermittelten Schubspannungen im Reifenlatsch. 

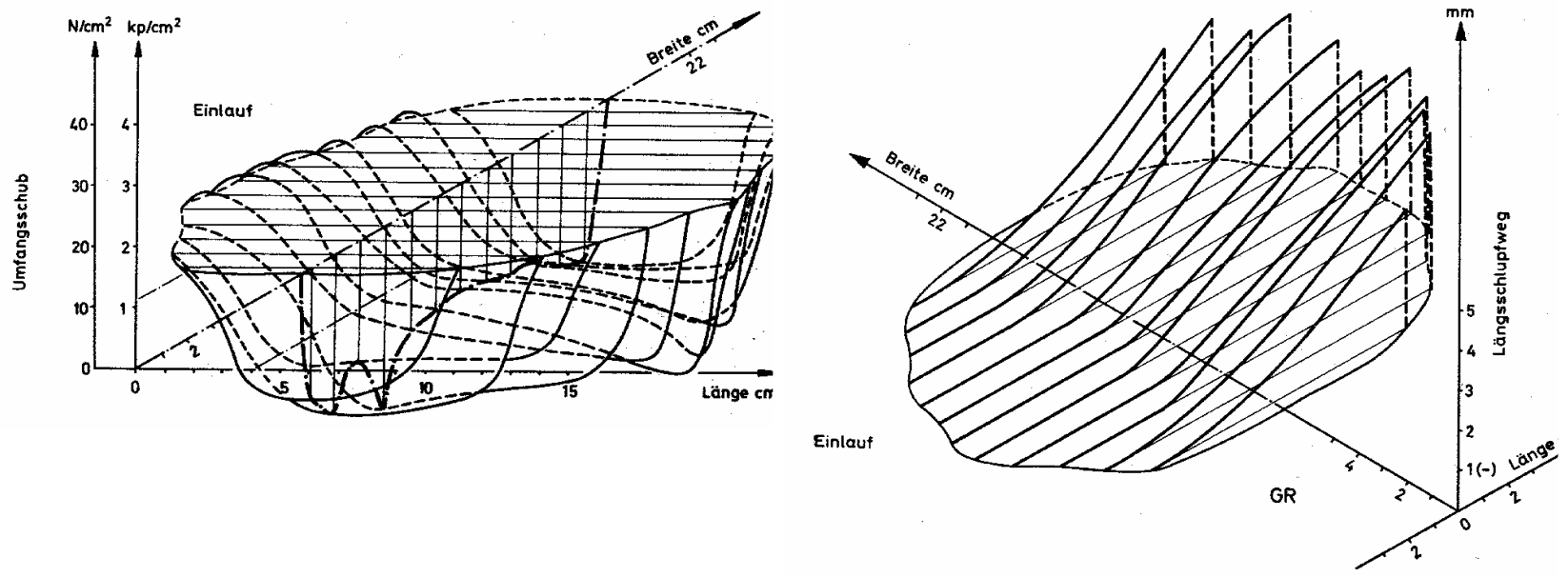

Bild 13: Schubspannungen und Gleitbewegungen in Längsrichtung in der Aufstandsfläche eines Pkw-Reifen unter Bremsschlupf nach Gerresheim [48], Radlast 4000 N, Umfangskraft 2000 N, s=9,4 \%

Auf der linken Seite sind die im Reifenlatsch eines gebremsten Reifens wirkenden lokalen Schubspannungen dargestellt, die rechte Seite enthält die daraus resultierenden Gleitbewegungen. Bei einem Bremsschlupf von annähernd $10 \%$ werden Gleitbewegungen von bis zu 6 mm erreicht. Die Gleitbewegungen setzen dabei etwa in der Mitte des Reifenlatsches ein und dauern, bei in etwa konstanter Gleitgeschwindigkeit, bis zum Ende der Kontaktzone an.

Seitz [109] führte ähnliche Untersuchungen auf einer Stahltrommel mit Geschwindigkeiten bis 120 $\mathrm{km} / \mathrm{h}$ durch. Neben diesen grundlegenden Forschungen sind vor allem die Arbeiten von Cooper [25], Borgmann [14], Farlopulus [41] und Roth [101] erwähnenswert. Fujikawa [42] untersuchte lokale Gleitbewegungen mit Hilfe eines optischen Verfahrens.

Eine Arbeit, die auch auf einem Außentrommelprüfstand durchgeführt wurde, ist die gemeinsame Dissertation von Günther und Paech [58].

Alle in der Literatur enthaltenen Untersuchungen wurden auf Flachbahn- oder Außentrommelprüfständen durchgeführt, die über eine Glas- oder Stahloberfläche verfügten. Untersuchungen der Gleitbewegungen auf realistischen Oberflächen sind nicht bekannt. Die Ursache dafür ist sicher in der Art der Gleitwegmessung zu sehen. Ein mechanischer Wegaufnehmer und vielmehr noch das optische Verfahren benötigen spezielle, sehr ebene Oberflächen, die zudem im Falle des mechanischen Aufnehmers mit einer Öffnung versehen werden müssen. Speziell diese Öffnung, in der Regel ein Schlitz, kann das Ergebnis verfälschen. Durch das Eindringen von Gummi in den Meßspalt werden elastische Deformationsanteile gemessen, die nicht eindeutig Gleitbewegungen zugeordnet werden können. 
In der vorliegenden Arbeit werden erstmals Messungen von Gleitbewegungen auf realistischen Oberflächen vorgestellt, auf denen zudem das Reibwertniveau durch Aufbringen von Zwischenmedien variiert wurde.

\subsubsection{Meßtechnik im Reifen, Reifensensoren}

Im Unterschied zu fahrbahnseitigen Messungen der Phänomene in der Reifen-Fahrbahn Kontaktzone finden sich in der Literatur sehr viel weniger Quellen zur Messung des Reifenverformungsverhaltens. Eine frühe Quelle sind die Arbeiten von Kern [71], [72], [73], der sich mit Hilfe von speziellen Dehnungsmeßstreifen für besonders große Dehnungen einen Einblick in das Verformungsverhalten von Reifen verschaffte.

Bild 14 enthält eine Darstellung der Ergebnisse dieser Messungen.

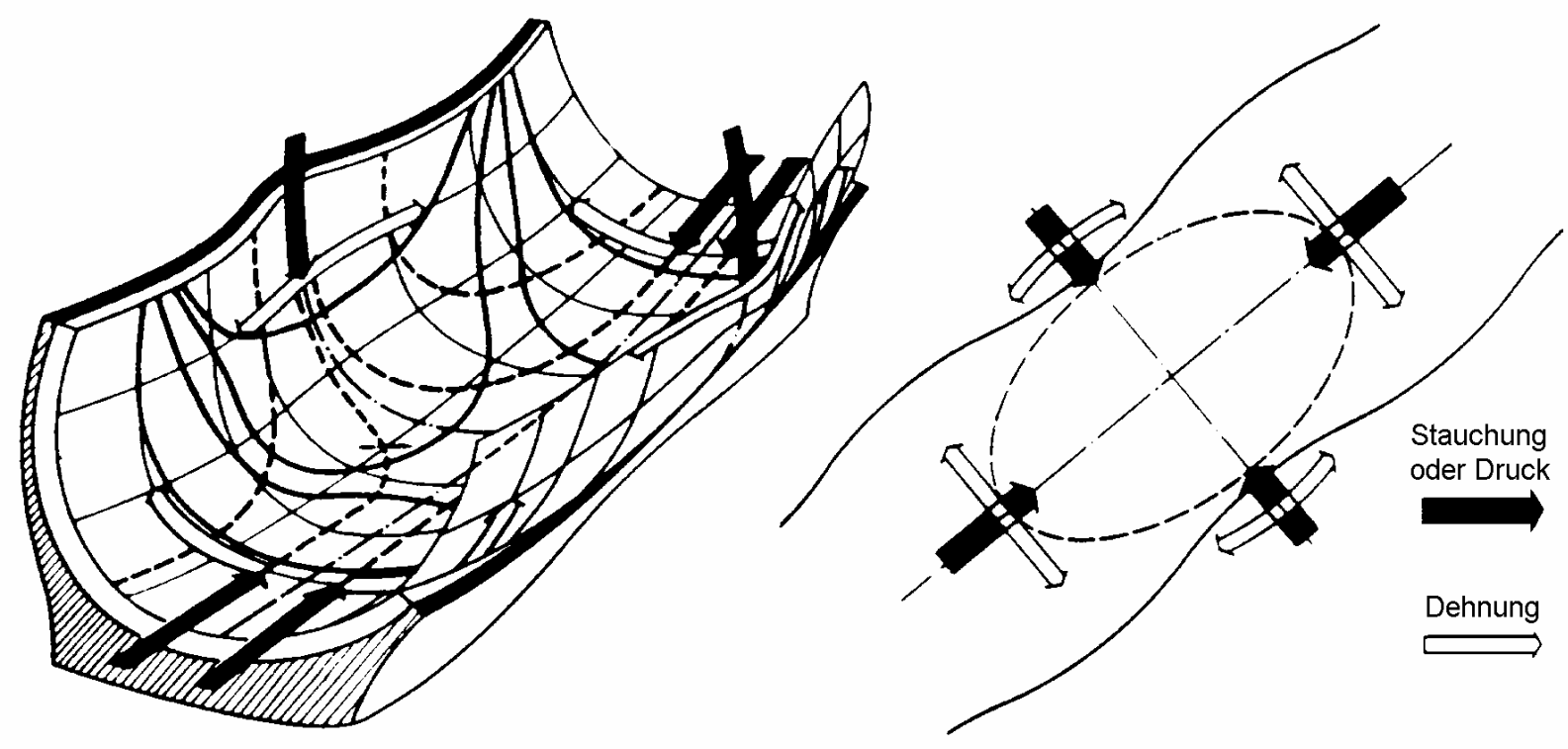

Bild 14: Messung abplattungsbedingter Verformungen im Reifen nach Kern [73]

Insbesondere die abplattungsbedingten Belastungen der Reifenstruktur, die sich ausgehend von der Kontaktzone über die gesamte Reifenkontur in Form von Stauchungen und Dehnungen äußern, konnten damit nachgewiesen werden. Die Isolierung reibwertrelevanter Schubspannungen in der Aufstandsfläche war mit diesem Aufbau jedoch nicht möglich. Neben dieser Arbeit verwendete auch Hurry [64] spezielle Dehnungsmeßstreifen. Biedermann [10] und Clark [22] beschäftigten sich mit verschiedenen Meßaufbauten zur Erfassung der Cordbeanspruchungen im abrollenden Reifen. 
Neugebauer und Grubisic [88], [89] wählten einen anderen Ansatz und verwendeten neben Dehnmeßaufnehmern Wegaufnehmer zur Beschreibung der Bewegungen eines Reifenpunkts auf der Innenseite relativ zur Felge. Bild 15 zeigt zwei Ausführungen dieser Meßanordnung.
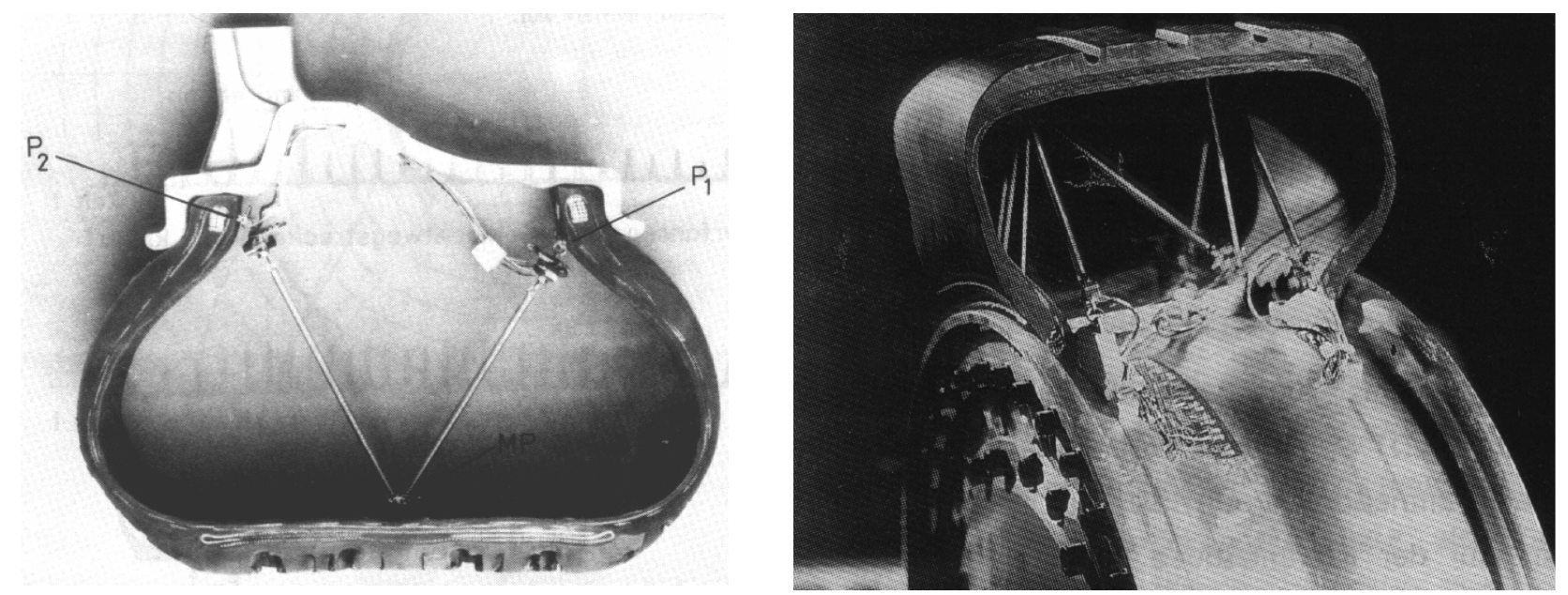

Bild 15: Aufnehmer zur Erfassung globaler und lokaler Reifenverformungen nach Neugebauer [89], Rupp und Grubi$\operatorname{sic}[102]$

Auch hiermit kann zwar das globale Verformungsverhalten des Reifens erfaßt werden, den lokalen Schubspannungen in der Fahrbahn entsprechende, reifenseitige Messungen können damit jedoch nicht erfolgen. Benson [9] stellte einen Profilverformungssensor zur Bestimmung der Wasserdicke unter einem im Aquaplaningbereich betriebenen Reifens vor.

Die in Darmstadt entwickelte und erstmals von Roth [101] verwendete Reifensensorik nimmt innerhalb dieser Arbeiten eine Sonderstellung ein. Durch die Messung von Verformungen des Laufstreifens relativ zum Gürtel gelang erstmals die reifenseitige Messung von Effekten, die den Schubspannungen in der Aufstandsfläche von Reifen äquivalent sind. Roth verwendete in seiner Arbeit überwiegend einen Sensor, der die Bewegungen eines Stiftes erfaßt, der durch den Stahlgürtel des Meßreifens in den Laufstreifen gesteckt war. Roth konnte mit diesem Sensor der 1. Generation bereits grundlegende Erkenntnisse zur Verteilung von Profilementverformungen im Laufstreifen von Pkw-Reifen in Abhängigkeit von wesentlichen Betriebsparametern gewinnen. Es gelang auch, bereits am freirollenden Rad signifikante Veränderungen im Signalverlauf des Reifensensorsignals in Abhängigkeit vom jeweils vorherrschenden Reibwertpotentials zu detektieren. Diese Gradientenänderungen im Signal wurden von Roth mit Gleitvorgängen im Reifenlatsch bei Überschreitung des lokalen Reibwertmaximus erklärt. Die qualitative und quantitative Erfassung dieser Gleitvorgänge und die Korrelation mit den Reifensensorsignalen erfolgte jedoch nicht. Dennoch bildeten 
diese Effekte die Grundlage für die Reibwerterkennung am rotierenden Rad mit Hilfe der Darmstädter Reifensensorik.

Der Reifensensor der 1. Generation wurde bereits von Roth und Supke [115] zur 2. Generation weiterentwickelt und bildete die Basis für die Evolution der Sensoren in den letzten Jahren. Es wurden insgesamt vier verschiedene Sensorgenerationen in aufeinanderfolgenden Evolutionsstufen gebaut und erforscht. Das Funktionsprinzip der am Fachgebiet Fahrzeugtechnik verwendeten Sensoren beruht in allen Fällen auf der Messung der Bewegung eines Magneten mit Hilfe von Hallgeneratoren bzw. magnetoresisitiven Widerständen. Mit diesen wird die Veränderung des Magnetfeldes detektiert, die von der Bewegung des Magneten verursacht wird. Der Magnet befindet sich dabei direkt im Laufstreifen oder ist über einen geeigneten Mechanismus an die Profilelemente gekoppelt. In Bild 16 sind die verschiedenen Generationen in einer Übersicht dargestellt.

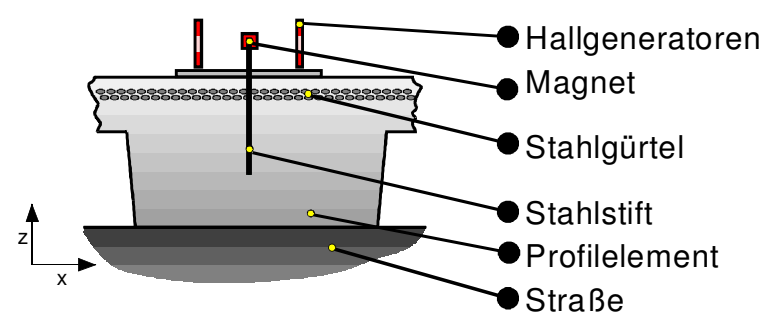

Reifensensor 1. Generation

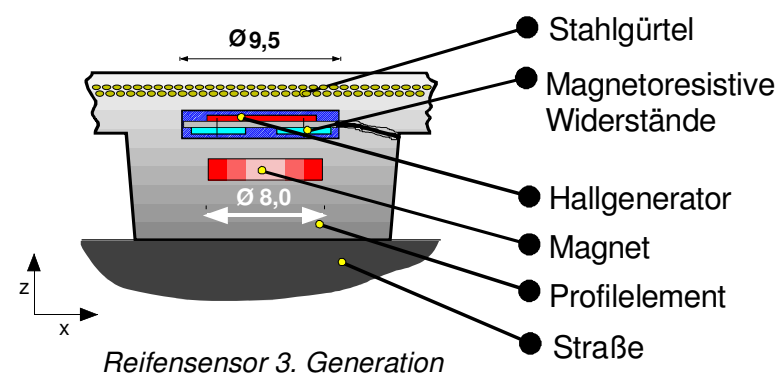

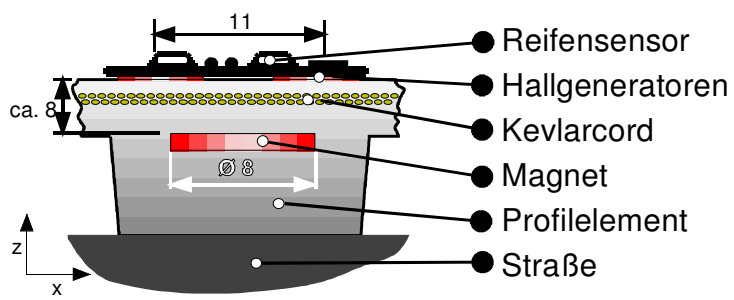

Reifensensor 2. Generation

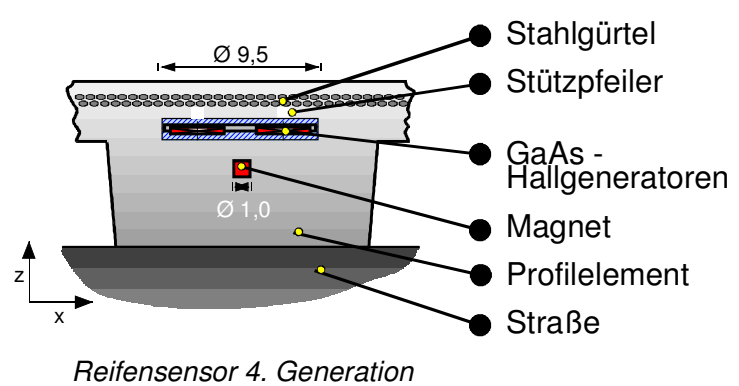

Reifensensor 4. Generation

Bild 16: Darmstädter Reifensensoren der 1. [101], 2. [112], 3. [115] und 4. Generation [59]

Ausgehend von der 1. Generation bis hin zur 4. Generation gelang ab der 3. Generation zunächst die Integration von Sensor und Magnet in den Laufstreifen. Daran anschließend konnten die Abmessungen der Sensorik so stark verringert werden, daß die Störung der Kinematik der Profilelemente für die Messung akzeptabel ist. Auf der einen Seite brachte die Verringerung der geometrischen Abmessungen des Sensors und insbesondere des Magneten den Vorteil einer geringeren Beeinflussung der Eigenschaften des Laufstreifen durch den eingebrachten Fremdkörper, auf der anderen Seite erfordern die geringen Abmessungen jedoch einen erheblichen Aufwand bei der Ap- 
plikation des Reifensensors. Der Sensor reagiert bei einem Magneten von nur einem Millimeter Durchmesser reagiert sehr empfindlich auf einen Positionierungsfehler von nur wenigen Zehntel Millimetern. Die Sensoren der 3. Generation wurden von Supke [115] entwickelt und nachträglich in das Profilelement eines fertigen Reifens eingebaut. Es gelang damit, grundlegende Untersuchungen der Profilelementmechanik am abrollenden Reifen durchzuführen. Daneben konnten von Ludwig [82] Phänomene des unregelmäßigen Reifenverscheißes analysiert werden. Bachmann beschäftigte sich in [5] und [7] mit dem Einsatz der Darmstädter Reifensensorik zur Erkennung des Fahrzustands am Fahrzeug und stellte ein Verfahren der Autokalibrierung von Reifensensoren im Betrieb vor [6]. Er verglich dabei die Sensoren der 2. und 3. Generation in Bezug auf ihr Potential für zukünftige Anwendungen im fahrzeugtechnischen Bereich zur Steigerung der Aktiven Sicherheit.

Die Signale der verschiedenen Sensorgenerationen spiegeln grundsätzlich die gleichen physikalischen Vorgänge im Laufstreifen von Reifen wider. Die Konstruktion und Anordnung der Sensoren beeinflußt jedoch sehr stark die Reaktionen der Sensorik auf diese Vorgänge. Der Signalinhalt kann sich dadurch in Abhängigkeit von den verwendeten Reifensensoren ändern, der Kraftzustand des Reifens bleibt jedoch gleich. Dieser Zusammenhang ist in Bild 17 dargestellt. Auf der linken Seite sind die Signale des Sensors der zweiten Generation bei einer Messung im freirollenden Zustand unter Standardbedingungen abgebildet. Die rechte Seite zeigt eine Messung unter gleichen Bedingungen mit der 3. Generation.
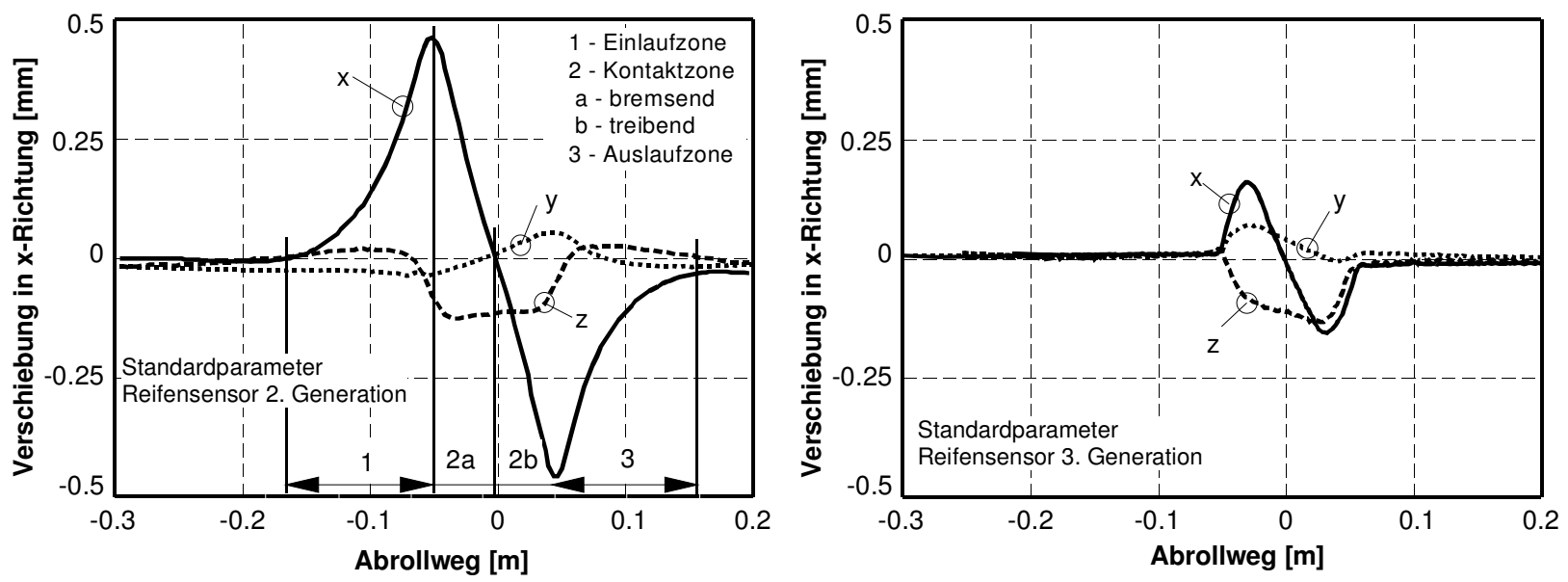

Bild 17: Standardsignale der Reifensensorgeneration 2 (links) und 3 (rechts) im Vergleich

Man erkennt am Reifensensor x-Signal den prinzipiellen Verlauf der Verformungen, die sich mit dem Borstenmodell des Reifens erklären lassen. Im Einlaufbereich des Reifens werden die Profilelemente entgegen der Drehrichtung des Rades verformt, im Auslaufbereich finden Verformungen 
mit der Drehrichtung statt. In der Mitte der Reifenaufstandsfläche sind die Schubspannungen und damit die Verformungen ungefähr Null. In Querrichtung sind, trotz der Applikation der beiden Sensoren in der Mitte des Reifens, kleine Verformungen zu erkennen. Diese sind durch Toleranzen in der Applikation der Sensoren und durch den Unterschied zwischen Kraft- und Geometriemitte des Reifens bedingt. Im Verhältnis zu den unter Seitenkräften entstehenden Verformungen sind diese Ausschläge jedoch gering.

In radialer Richtung läßt sich das flächenpressungsbedingte Einfedern des Profilelementes beobachten, das stark vom gewählten Innendruck des Reifens abhängt. Der Vergleich der beiden Sensoren zeigt insbesondere in x-Richtung signifikante Unterschiede. Während der Sensor der zweiten Generation schon weit vor dem Erreichen des eigentlichen Reifenlatschs Verformungen anzeigt, reagiert der Sensor der 3. Generation erst mit dem Einlauf in die Kontaktzone zwischen Reifen und Fahrbahn. Die Ursache für dieses unterschiedliche Verhalten liegt in der tieferen Einbauposition des Magneten beim Sensor der 2. Generation, der dadurch viel stärker von der Anbindung der Profilelemente untereinander beeinflußt wird. Dadurch zeigt dieser Sensor Verformungen an, die viel stärker von den globalen, abplattungsbedingten Verformungen des Reifentorus abhängen als von den lokalen Kraftverhältnissen in der Aufstandsfläche.

Der Sensor der 3. Generation ist durch seine Einbauposition näher an der Schnittstelle ReifenFahrbahn stärker durch den lokalen Kraftzustand an dieser Stelle beeinflußt. Er liefert ein detaillierteres Bild des Kraftzustands des einzelnen Profilelementes, während der Sensor der 2. Generation stärker integriert und einen globaleren Eindruck vom Zustand des Reifens zeigt.

Diese unterschiedlichen Charakteristika der Sensoren bedingen, daß für unterschiedliche Einsatzzwecke jeder Sensor spezifische Vor- und Nachteile hat, prinzipiell jedoch beide ihre Daseinsberechtigung haben.

Die hier vorgestellten Untersuchungen wurden mit dem Reifensensor der 2. Generation durchgeführt. Für das in Kapitel 2.3 vorgestellte Verfahren zur Messung lokaler Gleitvorgänge ist es notwendig, die Profilelementverformungen relativ zum Reifengürtel zu messen. Der Reifensensor der 3. Generation erfüllt diese Voraussetzung nicht, da die Platine innerhalb des Laufstreifens Bewegungen relativ zum Gürtel ausführen kann, die das Ergebnis der Gleitmessung verfälschen können.

Bild 18 zeigt fotografische Aufnahmen der beiden Sensorgenerationen. 

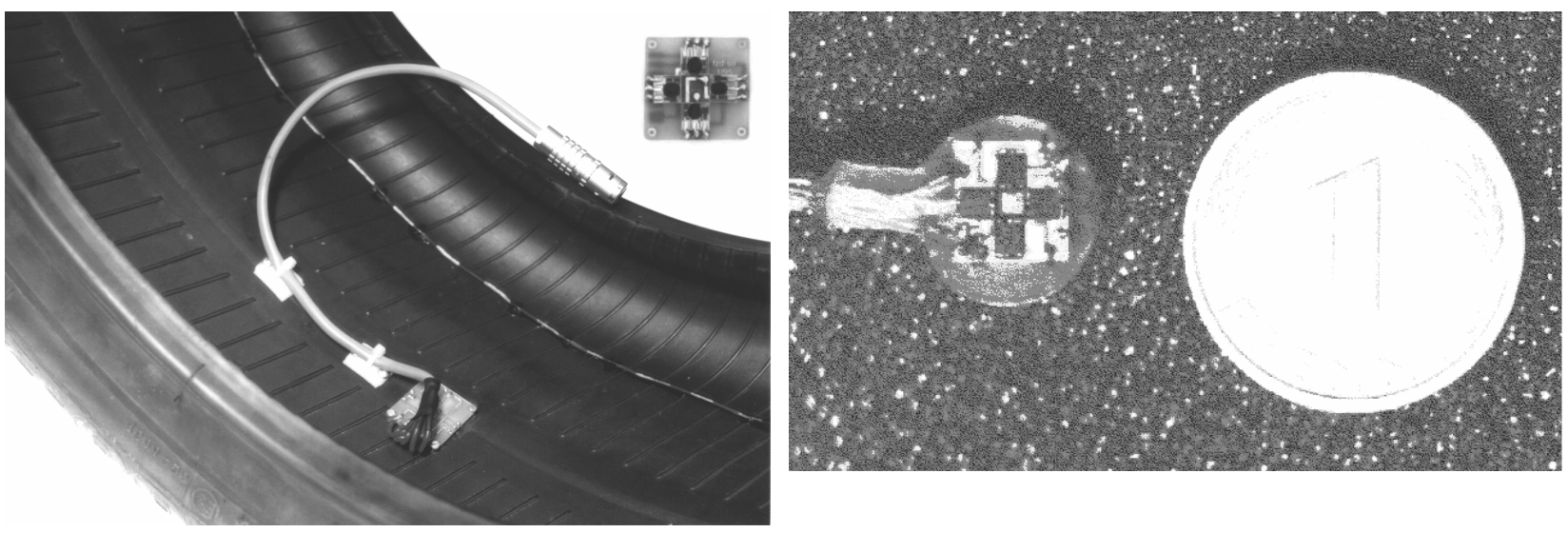

Bild 18: Reifensensorgeneration 2 im Reifen montiert (links) und Generation 3 im Größenvergleich (rechts)

\subsection{Fazit}

Das Studium der Literatur liefert, ausgehend von den viskoelastischen Eigenschaften des Gummis über die dadurch bedingten Eigenschaften der Reibung von Gummiproben bis hin zur Messung und Analyse von Reibwert-Schlupf-Kurven am Gesamtsystem Reifen-Fahrbahn, eine Vielzahl von Quellen zu den Mechanismen der Gummireibung. In der Regel sind insbesondere die Untersuchungen an den Subsystemen für den jeweils betrachteten Teil der Gesamtwirkungskette der ReifenFahrbahn Reibung schlüssig. An den Schnittstellen, dem Zusammenspiel der einzelnen Effekte, die sich von Phänomenen auf molekularer Ebene über die lokalen Effekte in der Aufstandsfläche zu den am Fahrzeug auftretenden Gesamtkräften am Rad summieren, besteht jedoch durchaus noch Forschungsbedarf.

Wie bereits von Bachmann in [3] festgestellt, bestehen an einigen Stellen noch überraschende Lücken im Verständnis der Gesamtzusammenhänge. Besonders für die Übertragung der verschiedenen Mechanismen der Gummireibung wie Adhäsion und Hysterese nach der vereinheitlichten Reibungstheorie von Kummer und Meyer [78] auf die daraus resultierenden globalen Effekte am Reifen zeigt sich, daß den lokalen Effekten in der Aufstandsfläche, die das Bindeglied zwischen den grundlegenden chemisch- physikalischen Ansätzen und den am Reifen erzeugten Kräften darstellen, bisher zuwenig Beachtung geschenkt wurde.

In einigen Quellen finden sich Aussagen über Schubspannungen, Verformungen und Gleitwege im Reifenlatsch von Pkw-Reifen. Diese Erkenntnisse wurden auch genutzt, um z.B. mit der Forderung nach gleichmäßiger Schubspannungsverteilung im Reifenlatsch im Zusammenhang mit dem Übergang vom Diagonal- zum Radialreifen Verbesserungen des Verschleiß- und Reibverhaltens von 
Reifen zu erzielen. Eine weiterführende Übertragung der Erkenntnisse auf einen übergreifenden Ansatz zum besseren Verständnis der Reifen-Fahrbahn-Reibung ist bis jetzt jedoch nicht erfolgt. Die Ursache dafür liegt sicher in der Tatsache, daß im Gegensatz zu Untersuchungen im Labor an einzelnen Proben und zu Messungen der Reibwert-Schlupf Charakteristik am Gesamtsystem die dazwischen liegenden Phänomene im Laufstreifen insbesondere meßtechnisch schwer zugänglich sind. An dieser Stelle können die am Fachgebiet Fahrzeugtechnik entwickelten Reifensensoren Einblicke verschaffen, die mit anderen Meßmethoden nicht möglich sind.

Mit einer zusätzlichen Sensorik zur Erfassung der lokalen Gleitvorgänge soll in dieser Arbeit versucht werden, Erkenntnisse zu gewinnen, die ein verbessertes Verständnis des wirkenden Gesamtsystems ermöglichen. Dazu werden auch erstmals Messungen von Gleitbewegungen auf realistischen Oberflächen und besonders unter Variation des Reibwertpotentials durchgeführt, die bisher nicht stattgefunden haben.

Die dabei gewonnenen Ergebnisse können nicht nur zur Untersuchung des Reifen-Fahrbahn Kontaktes genutzt werden, sondern dienen auch dazu, den Sensor selbst und seine Eigenschaften und Potentiale besonders mit Hinblick auf die von Roth erstmals vorgestellte Reibwerterkennung zu untersuchen. Auch hierbei ist es das Ziel, in einem übergreifenden Ansatz die Mechanismen zu erklären, die zu den bisher bereits beobachteten Effekten in den Reifensensorsignalen führen. Aus diesen Erklärungen sollen Aussagen abgeleitet werden, die unabhängig von der verwendeten Sensorik für die Verhältnisse in jedem rollenden Pkw-Reifen gültig sind.

Folgerichtig liegt der Schwerpunkt der in dieser Arbeit vorgestellten experimentellen und theoretischen Untersuchungen nicht auf der detaillierten Analyse jedes einzelnen Effekts, der beobachtet werden kann. Vielmehr sollen in einem Gesamtüberblick über alle wirkenden Effekte besonders die grundlegenden, mit größter Sicherheit isolierbaren Wirkzusammenhänge diskutiert werden. 


\section{Werkzeuge und Methodik der Versu- che}

\subsection{Prüfstand LINUS}

Messungen mit der $f z d$ Reifensensorik zur Erprobung und zum Vergleich der verschiedenen Sensoren werden zunächst auf Prüfständen durchgeführt. Wegen der guten Reproduzierbarkeit der Umgebungsbedingungen im Labor findet auch die Erforschung lokaler physikalischer Phänomene überwiegend unter Laborbedingungen statt. Ein wichtiges Werkzeug ist dabei der $f z d$ LinearReifenprüfstand LINUS, der von Supke [115] speziell für die Messungen mit den Reifensensoren angepaßt und erweitert wurde. Bild 19 zeigt eine Ansicht des Prüfstands mit seinen Funktionseinheiten.

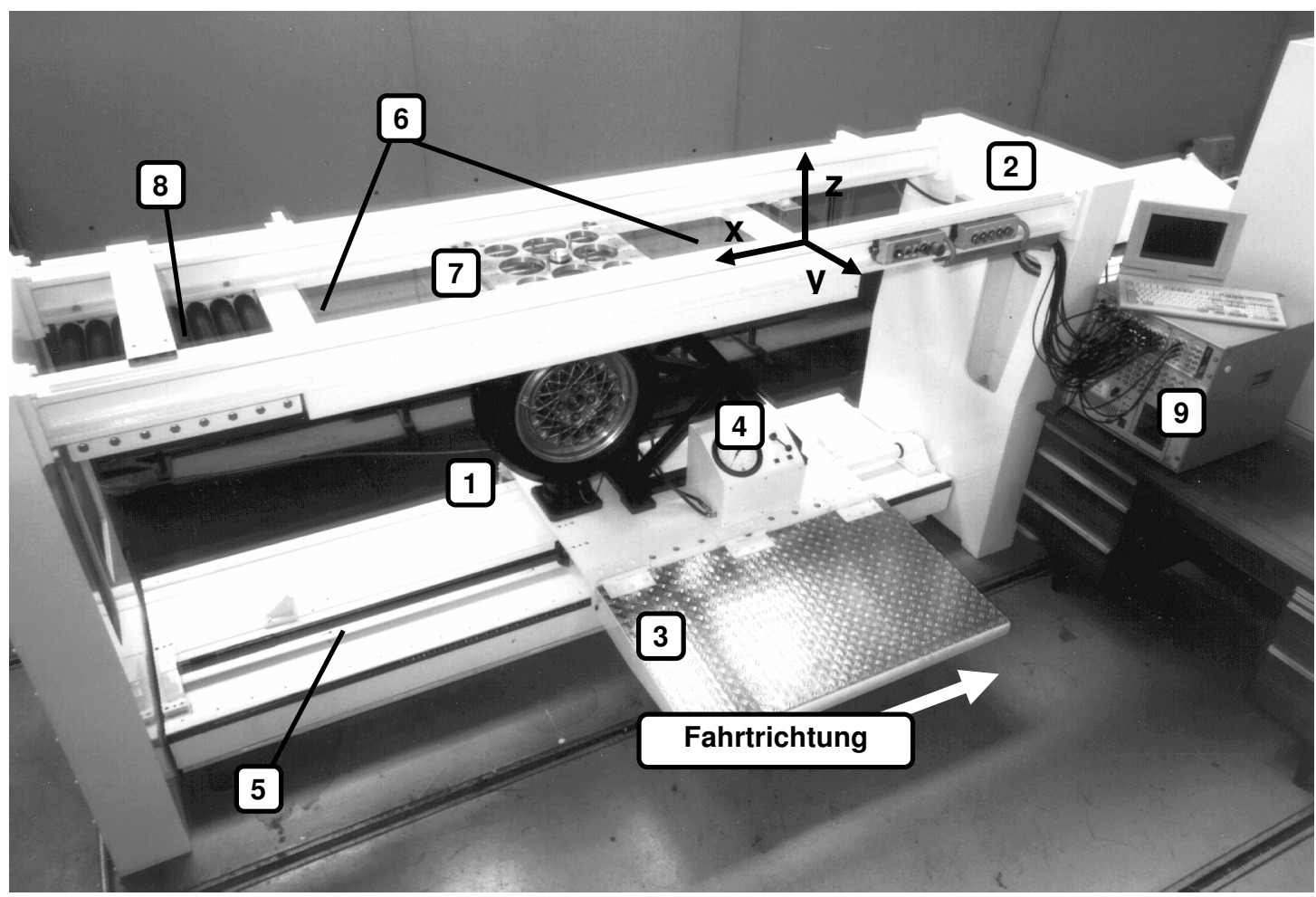

Bild 19: Reifenlinearprüfstand LINUS zur fahrbahnseitigen Untersuchung physikalischer Phänomene in der Aufstandsfläche abrollender Pkw-Reifen - (1) Meßreifen, (2) Rahmen, (3) Schlitten, (4) Radaufhängung, (5) Gewindespindel, (6) Acrylglas, (7) Meß- und Kalibrierplattform, (8) Rollenbahn, (9) Meßdatenerfassung nach Supke [115] 
Der Prüfstand besteht aus einer Plexiglasfahrbahn, auf der ein Pkw-Reifen pneumatisch angedrückt wird und mit langsamer Geschwindigkeit abrollt (0,014 m/s). Dabei können die auftretenden Kräfte im Reifenlatsch global und lokal über eine Kraftmeßplattform fahrbahnseitig gemessen werden. Es ist möglich, den Reifen unter Variation von Sturz, Schräglaufwinkel, Antriebs- oder Bremsmoment bei einer frei wählbaren Radlast definiert zu betreiben. Die Glasfahrbahn gestattet es, den Reifenlatsch während des Abrollens zu beobachten.

Die Fahrbahnoberfläche ist poliert und entspricht daher weder in ihren Materialeigenschaften noch in ihrer Textur einer realen Asphaltoberfläche. Dennoch wird ein Reibwert von ca. $\mu=0.9$ erreicht. Unter den genannten Einschränkungen sind die Meßergebnisse des Prüfstands durchaus auf die Straße übertragbar. Eine Veränderung des Reibwertniveaus, insbesondere eine Reduzierung, ist nur durch Aufbringen eines Zwischenmediums möglich. Hier hat sich Seifenlösung bewährt, die eine Verringerung des maximalen Reibwerts auf ca. $\mu=0.1$ bewirkt.

Neben dem lokalen Meßelement, einem Meßstempel, der auf einem Dreikomponentenkraftaufnehmer angebracht ist, können besonders auch aus den globalen Signalen der Meßplattform interessante Schlüsse gezogen werden. Diese Plattform ist an ihren vier Ecken in jeweils einer Dreikom-

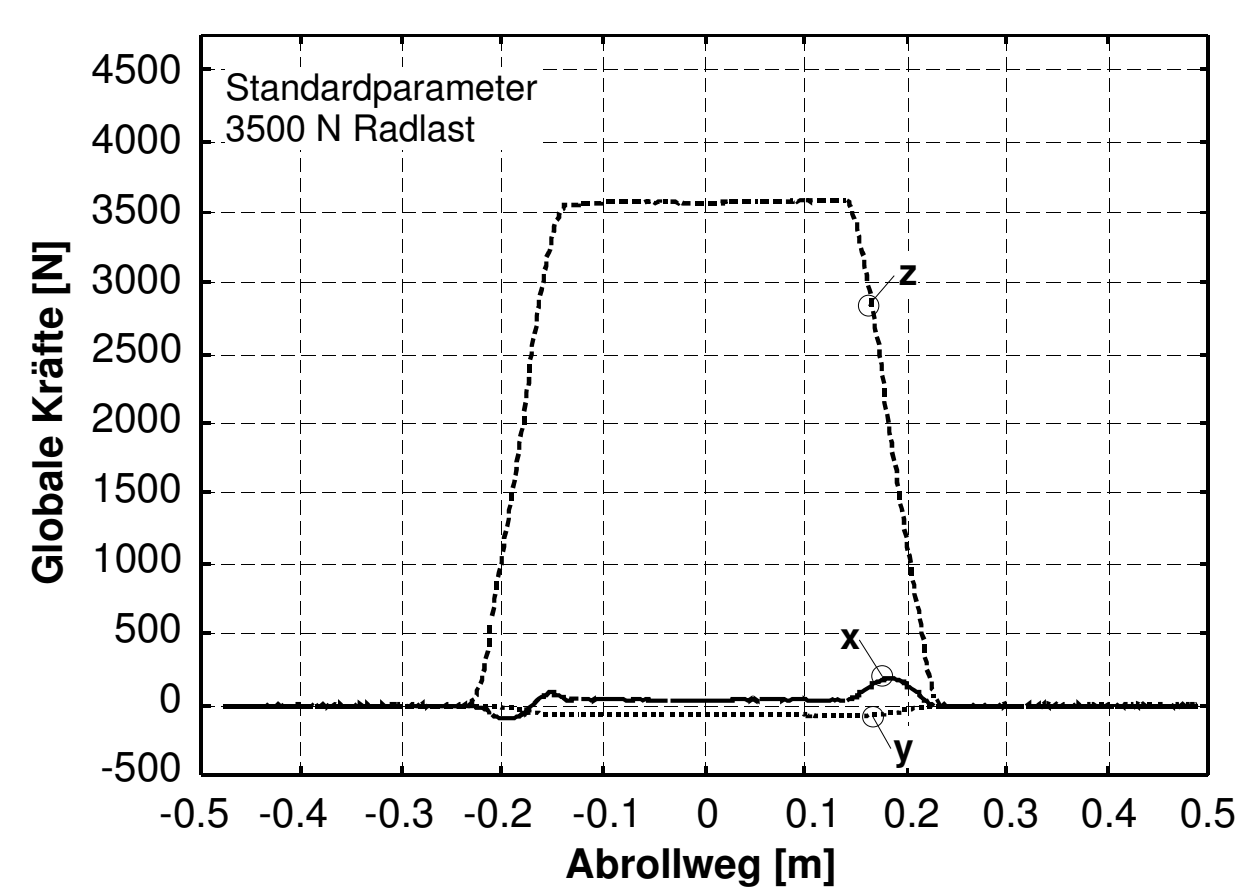

Bild 20: Standardsignale der globalen Meßplattform des Linearprüfstands LINUS ponentenkraftmeßdose gelagert. Die Berechnung der globalen Kräfte erfolgt durch die Summierung der Einzelkräfte in den Koordinatenrichtungen.

Bild 20 enthält die Signale der globalen Meßplattform unter Standardbedingungen.

Das z-Signal entspricht der Radlast und zeigt das Aufrollen des Reifens auf die Plattform im Steilanstieg des Signals und das danach erfolgende Abrollen. Das ySignal entspricht der vom Reifen produzierten Seitenkraft. Auch unter den Standardbedingungen eines freirollenden Rades ohne Schräglaufwinkel erzeugt der Versuchsreifen eine Seitenkraft, die mit ca. $70 \mathrm{~N}$ abgelesen werden kann. Die Ursache dafür liegt in der von der vom Idealzustand ab- 
weichenden Geometrie des Reifens aufgrund fertigungsbedingter Toleranzen. Das X-Signal gibt die lokalen Kräfte in Längsrichtung wieder. Da zu Beginn und am Ende der Plattform jeweils nur ein Teil des Reifens Kontakt mit der Fahrbahn hat, werden die sinusförmigen Schubspannungen sichtbar, die durch das Borstenmodell des Reifens erklärt werden können (vgl. Bild 7). Die Steigung der Signale der Plattform entsprechen an ihren beiden Kanten den lokalen Schubspannungen, allerdings integriert über die Reifenbreite. Während die Signale des lokalen Kraftmeßelements, das Schubspannungen direkt messen kann, in großer Zahl in der Arbeit von Supke [115] enthalten sind, sollen in dieser Arbeit die Meßergebnisse der globalen Plattform diskutiert werden. Der Vorteil der Plattform gegenüber dem Meßstempel liegt darin, daß an den geraden Kanten der Plattform beim Aufund Abrollen des Reifens bedeutend geringere Formschlußeffekte durch in den Trennspalt eindringendes Gummi entstehen als beim Ringspalt des lokalen Meßstempels. Damit können besonders die Auswirkungen von reduzierten Reibwerten, bei denen es zum Gleiten der Profilelemente auf der glatten Fahrbahn kommt, untersucht werden. Das lokale Meßelement liefert unter diesen Bedingungen, die in etwa den Verhältnissen auf Glatteis entsprechen, Ergebnisse, die stark von den formschlüssigen Kräften des Gummis im Ringspalt des Meßelements beeinflußt werden.

Zusammengefaßt ergeben sich für den Prüfstand LINUS folgende Technische Daten:

Tabelle 1: Technische Daten LINUS

\begin{tabular}{|l|l|l|}
\hline \multicolumn{1}{|c|}{ Parameter } & Wert & Genauigkeit \\
\hline Radlast & $0-5000 \mathrm{~N}$ & $\pm 5 \mathrm{~N}$ \\
\hline Seitenkraft & $\pm 2500 \mathrm{~N}$ & $\pm 2.5 \mathrm{~N}$ \\
\hline Längskraft & $\pm 2500 \mathrm{~N}$ & $\pm 2.5 \mathrm{~N}$ \\
\hline Geschwindigkeit & $0.0147 \mathrm{~m} / \mathrm{s}$ & $\pm 0.001 \mathrm{~m} / \mathrm{s}$ \\
\hline Schräglaufwinkel & $\pm 45^{\circ}$ & $\pm 0.2^{\circ}$ \\
\hline Sturzwinkel & $\pm 45^{\circ}$ & $\pm 0.2^{\circ}$ \\
\hline Lokale Schubspannungen & $\pm 2.4 \mathrm{~N} / \mathrm{mm}^{2}$ & $\pm 0.02 \mathrm{~N} / \mathrm{mm}^{2}$ \\
\hline Meßstempel & $\varnothing 3.6 \mathrm{~mm}$ & \\
\hline Ringspalt um Meßstempel & ca. $1.5 \mathrm{~mm}$ & \\
\hline
\end{tabular}




\subsection{Prüfstand IPS}

Zur Untersuchung dynamischer lokaler Effekte bei höheren Geschwindigkeiten wurde im Rahmen dieser Arbeit der Innentrommelprüfstand IPS der Bundesanstalt für Straßenwesen eingesetzt. Dieser Prüfstand bietet gegenüber dem Prüfstand LINUS den Vorteil, daß er eine realistische Asphaltoberfläche hat, die außerdem bewässert werden kann, um den Reibwert zwischen Reifen und Fahrbahn zu reduzieren.

Messungen auf realen Straßen, die z.B. mit Hilfe von Reifenmeßanhängern durchgefürt werden können, bieten ein noch höheres Maß an Realitätsnähe. Allerdings sind dabei die Betriebsparameter, besonders auf nassen Fahrbahnen, aufwendiger zu variieren und schwer zu erfassen. Der Wechsel von einer Fahrbahnoberfläche zu einer anderen ist dafür sehr viel schneller möglich als bei einem Innentrommelprüfstand, bei dem ein Wechsel der Fahrbahnkassetten mit den erforderlichen Anpassungsarbeiten mehrere Wochen in Anspruch nehmen kann.

Für die in dieser Arbeit durchgeführten experimentellen Arbeiten waren die speziellen Vorteile des Prüfstands ausschlaggebend (vgl. Kapitel 2.3). Die Vorrichtung zur Messung lokaler Gleitvorgänge kann prinzipiell zwar auch in realen Fahrbahnen eingebaut werden. Das Funktionsprinzip erfordert aber ein genaues Treffen einer bestimmten Stelle an Reifenumfang und -Breite. Dies ist unter vertretbarem technischen Aufwand nur in einem Prüfstand möglich.

Der Prüfstand IPS wurde im Jahr 1974 errichtet und diente zunächst hauptsächlich zur Untersuchung des Fahrbahnverschleißes durch Spikesreifen. Die Konzeption war allerdings von vornherein auf ein breiteres Anwendungsspektrum, wie z.B. Reibwert- und Schnellaufuntersuchungen, ausgerichtet, Keller [69]. In der Vergangenheit wurde der Prüfstand zur Anpassung an sich ändernde Anforderungen und Forschungsthemen in seinem Funktionsumfang stark erweitert. Er stellt heute ein sehr breit einsetzbares Forschungsinstrument zur Thematik des Reifen-Fahrbahn Kontaktes dar.

Bild 21 zeigt eine Gesamtansicht des Reifenprüfstands in der Bundesanstalt für Straßenwesen. 


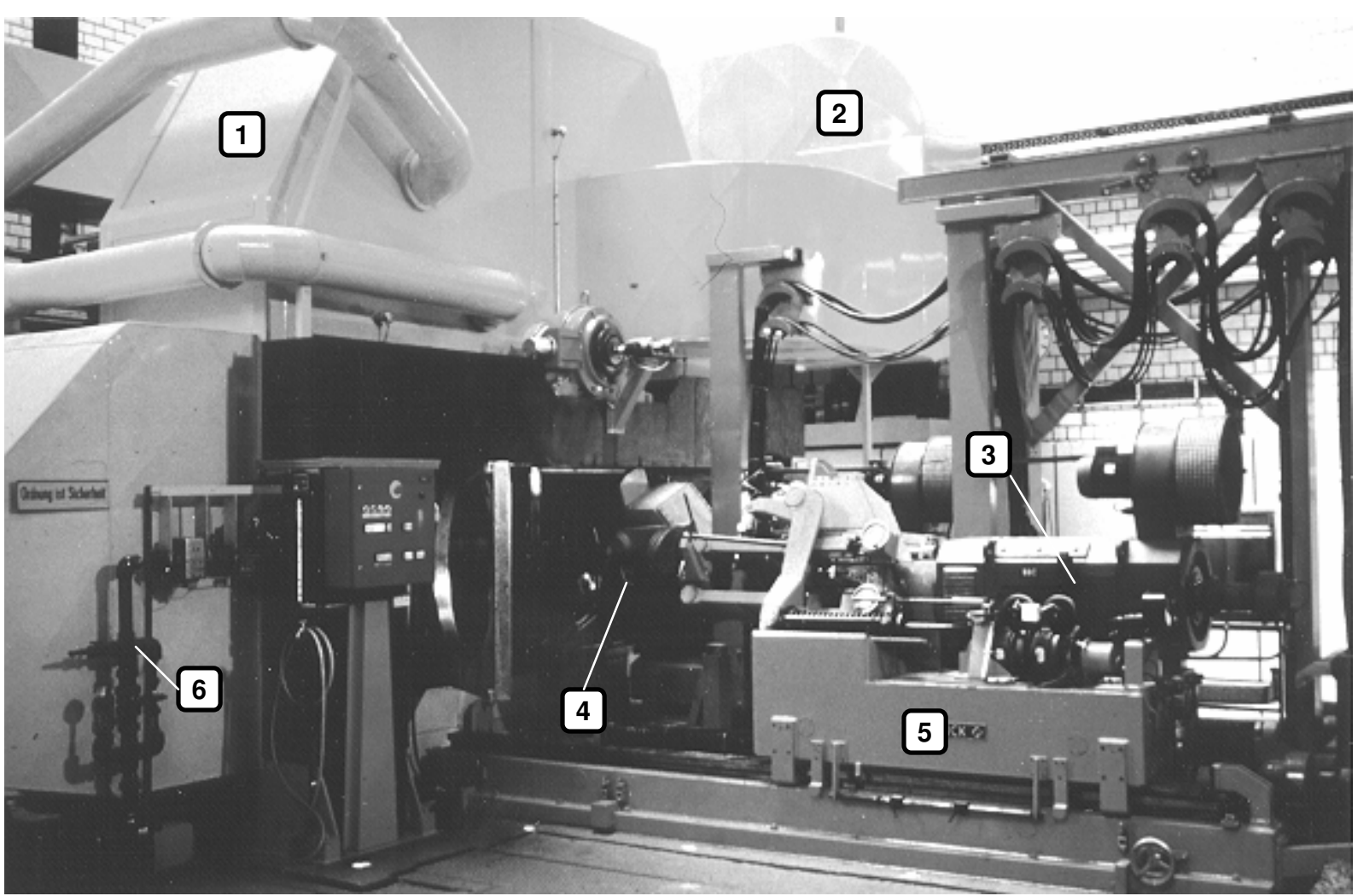

Bild 21: Gesamtansicht Innentrommelprüfstand IPS der Bundesanstalt für Straßenwesen - (1) Trommelgehäuse, (2) Klimatisierungskanal, (3) Radmotor, (4) Meßrad, (5) Radschlitten 1, (6) Wasserversorgung

Im Vordergrund befindet sich einer der beiden Radschlitten mit Antriebsmotor bzw. Bremsgenerator und montiertem Pkw Rad, im Hintergrund das Klimagehäuse, das die Prüfstandsfahrbahn umgibt. Durch eine Öffnung wird der Radschlitten mit dem Versuchsreifen eingefahren. Die Trommel rotiert im Inneren des Klimagehäuses.

Der Innendurchmesser der mechanisch gelagerten und einseitig offenen Lauftrommel beträgt 3,8 m. Der Fahrbahnbelag wird in 12 auswechselbaren Kassetten auf der Innenseite der Trommel montiert. Die Beläge sind bis zu $80 \mathrm{~mm}$ stark und werden mit Hilfe eines speziellen Verfahrens so hergestellt, daß sie in Aufbau und Oberflächeneigenschaften realen Fahrbahnbelägen entsprechen.

Der Antrieb der Trommel erfolgt über einen drehzahlgeregelten Gleichstrommotor. Die Höchstgeschwindigkeit an der Fahrbahnoberfläche beträgt mit Standardkassetten $150 \mathrm{~km} / \mathrm{h}$ (Umfangsgeschwindigkeit). Bei Bestückung mit Leichtkassetten, bei denen die Dicke des Fahrbahnbelages auf $40 \mathrm{~mm}$ begrenzt ist, kann die Geschwindigkeit bis auf $230 \mathrm{~km} / \mathrm{h}$ erhöht werden. 


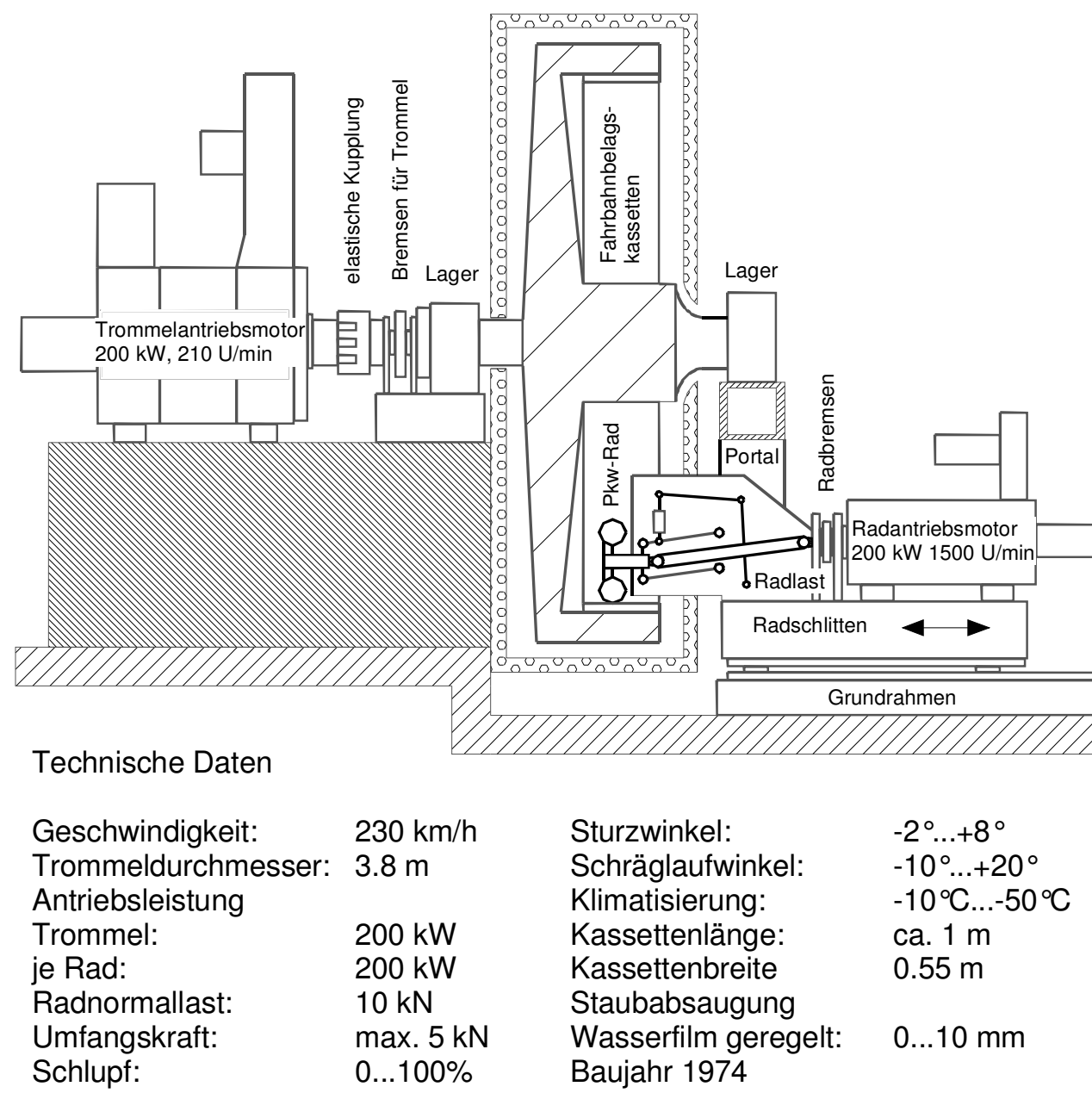

Bild 22: Aufbauschema Innentrommelprüfstand IPS der Bundesanstalt für Straßenwesen nach Keller [69]

Bild 22 zeigt den schematischen Aufbau sowie die wichtigsten technischen Merkmale des Prüfstands.

Im unteren Bereich der Trommel können ein oder zwei an getrennten Radschlitten montierte PkwRäder in die Trommel eingefahren werden und auf der Fahrbahn abrollen. Die Räder werden über elektromotorisch verstellbare Schraubenfedern mit einer Normalkraft bis zu $10 \mathrm{kN}$ belastet. Die Messung der Radlast erfolgt dabei über eine in der Radaufhängung integrierte Kraftmeßdose.

Über eigene drehzahlgeregelte Gleichstromantriebe können die Räder mit Umfangskräften von bis zu $5 \mathrm{kN}$ sowohl antreibend als auch bremsend betrieben werden. Dabei werden die auftretenden Umfangskräfte am Rad über die Motorströme mit Hilfe des vorher kalibrierten dynamischen Reifenhalbmessers ermittelt, Sollfrank [111].

Die Vorgabe der Brems- bzw. Umfangskraft kann über die Vorgabe von Schlupf oder Umfangskraft vorgenommen werden. Die Prüfstandstrommel mit Fahrbahn ist von einem geschlossenen Gehäuse mit Wärmeisolierung umgeben. In Kombination mit einem Kühlaggregat und einem 
mehrstufigen Heizregister kann die Luft und damit auch die Fahrbahntemperatur zwischen $-10^{\circ} \mathrm{C}$ und $+50^{\circ} \mathrm{C}$ eingeregelt werden .

Die hier beschriebenen Messungen wurden auf einem standardmäßigen Asphaltbetonbelag vom Typ AB 0/11 S mit einer Ausgangsstärke von 80 mm durchgeführt. Die Griffigkeit der Fahrbahn liegt über 55 SRT Einheiten. Dieser Wert liegt innerhalb der auf dem öffentlichen Straßennetz anzutreffenden Bandbreite, FGSV [32].

Das Nachlassen der Griffigkeit durch die Polierwirkung der Versuchsreifen kann entweder durch Befahren mit einem Spikesreifen unter Umfangskraft oder durch eine kontinuierlich arbeitende Aufrauheinrichtung ausgeglichen werden. Die Installation einer kontinuierlichen Aufrauheinrichtung am Innentrommelprüfstand erfolgte im Rahmen einer vorhergehenden Untersuchung [35]. Dabei wird ein Hartmetallkette eingesetzt, die auf der Fahrbahn schleift und dadurch die Oberfläche in Abhängigkeit von der Anzahl der Trommelumdrehungen, während derer sie "im Eingriff ist", wieder aufrauht.

In die Fahrbahn ist eine ca. $40 \mathrm{~cm}$ breite und $15 \mathrm{~mm}$ tiefe Spurrille eingeschliffen, die durch die seitlich hochstehenden Stege einen zu schnellen Abfluß des Wassers verhindert. Der Prüfstand verfügt über eine geregelte Bewässerungseinrichtung, die mit zwei Umwälzpumpen, zwei Drosselventilen, einem Durchflußmesser, einer Sprühdüsenreihe unmittelbar über der Fahrbahn sowie einer Meßeinrichtung für die Wasserfilmhöhe versehen ist. Die Sprühdüsenreihe ist hinter dem Prüfrad so angeordnet, daß das auf die Fahrbahn auftreffende Wasser während des anschließenden Trommelumlaufs Gelegenheit hat, sich gleichmäßig zu verteilen und zu beruhigen, bevor es anschließend von dem Prüfrad überrollt wird. Die Bestimmung der aktuellen Wasserfilmhöhe erfolgt im Abstand von ca. 1,1 m vor dem Prüfrad mit Hilfe eines kapazitiv arbeitenden Abstandssensors. Der Meßbereich des Sensors beträgt 0 bis $10 \mathrm{~mm}$ mit einer Auflösung von $\pm 0,1 \mathrm{~mm}$. Mit Hilfe einer Regeleinrichtung, die aus dem Abstandssensor, einem PC und den oben erwähnten Drosselventilen besteht, können definierte Wasserfilmhöhen auf der Fahrbahn mit einer Genauigkeit von $\pm 0,1 \mathrm{~mm}$ eingestellt und konstant gehalten werden, Heinrichs [61].

Der Einfluß des Krümmungsradius der Fahrbahn auf das Reifenverhalten kann nach einer früheren Untersuchung bei einem Trommelradius ab 2 Metern vernachlässigt werden, Krempel [76]. Die Übertragbarkeit der Ergebnisse unter Aquaplaningbedingungen auf die Verhältnisse realer Straßen bei Nässe wurde innerhalb dieser Arbeit untersucht und in einem gesonderten Forschungsbericht dokumentiert [40]. Es konnte beim Vergleich der Messungen im IPS mit Messungen eines Reifenmeßanhängers des Fachgebiets Fahrzeugtechnik kein Einfluß der Fliebeschleunigung, die im In- 
nentrommelprüfstand auf den Wasserfilm wirkt, festgestellt werden. Die Ergebnisse aus dem IPS können daher als repräsentativ für reale Bedingungen gelten.

Neben der Messung der Umfangskraft über die Motorströme am Radantrieb wurde der Prüfstand in jüngerer Zeit um eine Radaufhängung erweitert, die mit 6 Kraftmeßdosen und einer aufgelösten Konstruktion aus 6 verschiedenen kinematisch unabhängigen Lenkern die am Rad wirkenden Kräfte und Momente messen kann. Mit dieser neuartigen Aufhängung können somit neben den Bremskräften auch Kräfte in Folge von Schräglauf- bzw. Sturzwinkeln und Überlagerungen davon gemessen werden. Da bisher keine Veröffentlichung zu dieser Konstruktion erfolgt ist, wird an dieser Stelle die Funktionsweise der Einrichtung beschrieben.

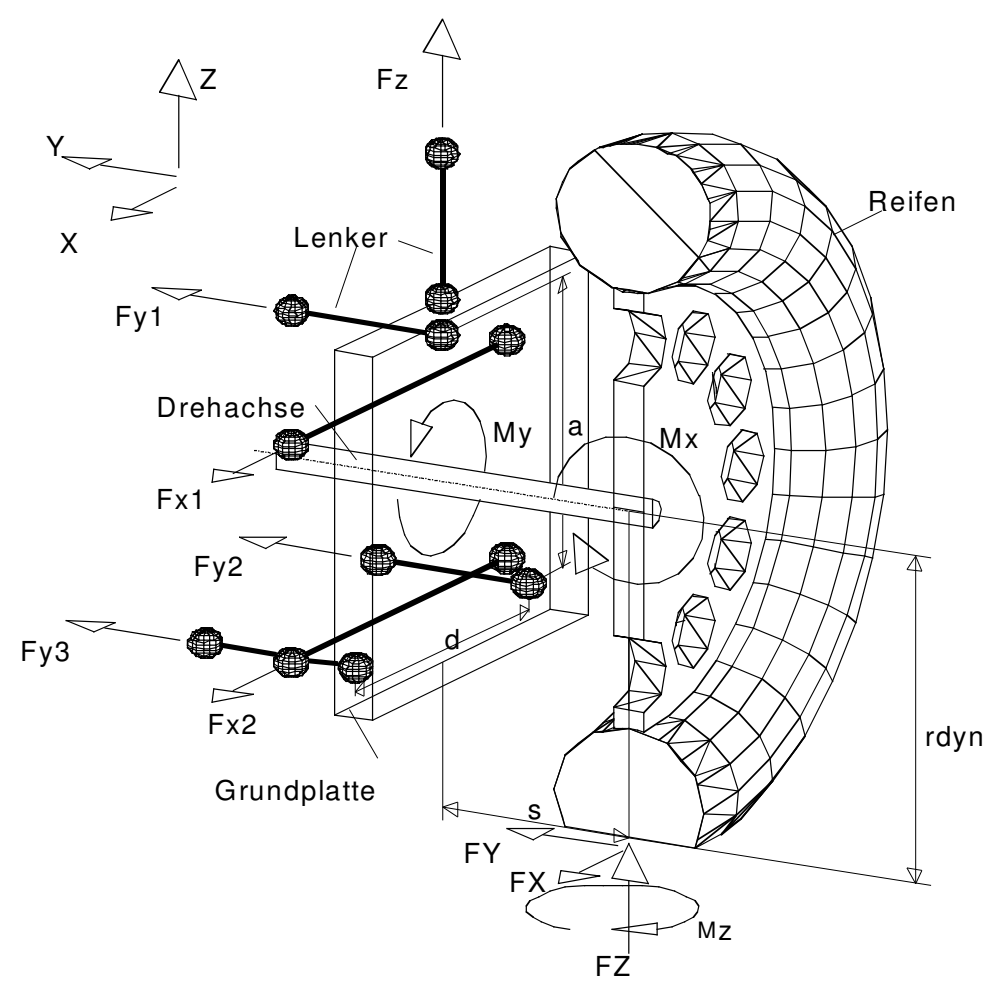

Bild 23: Radaufhängung zur Kraft- und Momentenmessung im In- ähnliche Beziehungen unter Berücknentrommelprüfstad IPS, schematisch
In Bild 23 ist das Wirkprinzip der Radaufhängung für den Prüfstand IPS dargestellt. Die in der Zeichnung dargestellten beidseitig sphärisch gelagerten Lenker können Kräfte jeweils nur in ihrer Längsrichtung aufnehmen.

Die am Rad wirkenden Kräfte können daher aus den resultierenden Lenkerkräften in den entsprechenden Koordinatenrichtungen summiert werden.

Für die drei Momente am Rad gelten sichtigung der geometrischen $\mathrm{Ab}$ -

stände. Die Strecken a und d sind Konstanten, die Strecke s ist variabel, der Durchmesse $r_{\text {dyn }}$ (in der Zeichnung der Abstand der Radachse zur Fahrbahnoberfläche, in der Realität ein Wert zwischen diesem Abstand und dem aus dem dynamischen Abrollumfang ermittelten Radius) muß berechnet werden.

Für die Berechnung der Kräfte gelten folgende Formeln: 


$$
\begin{aligned}
& F X=-\sum_{i=1}^{2} F x i \\
& F Y=-\sum_{i=1}^{3} F y i \\
& F Z=-F z
\end{aligned}
$$

Das Moment um die x-Achse kann zur Berechnung des kraftwirksamen Reifenhalbmessers herangezogen werden. Es entsteht aus der Seitenkraft und dem Hebelarm des Reifens. Bei der Bestimmung aus den Lenkerkräften muß zusätzlich das Moment aus der Radlast und dem Abstand der Radmitte zur Lenkerplattform s berücksichtigt werden. Das Blindmoment aus dem Gleichlaufgelenk der Antriebswelle, das unter Schräglaufwinkel und Bremskraft auftritt, wird vernachlässigt (zulässig nur für kleine Beugewinkel $<4^{\circ}$, bzw. Momente), so daß folgende Beziehungen gelten:

$$
M x=+F z \cdot s+(-F y 1+F y 2+F y 3) \cdot \frac{a}{2}
$$

mit:

$$
M x=-F Y \cdot r d y n
$$

folgt:

$$
r d y n=\left(-F z \cdot s+(F y 1-F y 2-F y 3) \cdot \frac{a}{2}\right) \cdot \frac{1}{-F y 1-F y 2-F y 3}
$$

Die Strecke s ist vom Sturzwinkel abhängig und muß bei der Berechnung variabel einfließen. Wird der Lenkrollhalbmesser nicht auf die jeweilige Reifen- Felgenkombination eingestellt, muß berücksichtigt werden, daß die Strecke s unter diesen Umständen auch vom Schräglaufwinkel abhängt. Das Rückstellmoment Mz setzt sich aus folgenden Momenten zusammen:

- Moment aus Reifennachlauf und Seitenkraft (Rückstellmoment),

- Moment aus Längskrafthebelarm und Längskraft,

- Moment aus Lenkrollhalbmesser, Spreizung und Radlast,

- Moment aus Radnachlauf und Seitenkraft, 
- Moment aus Radnachlauf und Längskraft.

Die beiden letzten Momente fallen wegen Nachlauf $=0$ für die gegebene Radaufhängung weg. Das dritte Moment ist wegen Lenkrollhalbmesser $=0$ vernachlässigbar klein, wenn auch noch vorhanden. Ferner tritt noch ein Blindmoment aus der Beugung des Gleichlaufgelenks der Antriebswelle auf, wenn ein Antriebsmoment und Sturz vorhanden sind. Dieses Moment wird aber ebenfalls vernachlässigt.

So ergibt sich das gesuchte Rückstellmoment des Reifen in diesem Fall aus:

$$
M z=(F y 2-F y 3) \cdot \frac{d}{2}+(F x 1+F x 2) \cdot s
$$

Für die Strecke s gilt das bereits Gesagte: Zur Bestimmung des Rückstellmoments muß auf jeden Fall der Lenkrollhalbmesser den Wert 0 annehmen, damit die oben getroffenen Annahmen erfüllt sind (insbesondere Vernachlässigung des Moments aus Lenkrollhalbmesser, Spreizung und Radlast). Das Brems- bzw. Antriebsmoment My kann bei der gegebenen Konstruktion nicht direkt aus den Lenkerkräften bestimmt werden, da es sich über die Gelenkwelle am Elektromotor abstützt. Es muß daher aus :

$$
M y=F X \cdot r d y n
$$

bzw:

$$
M y=-(F x 1+F x 2) \cdot r d y n
$$

berechnet werden. Für die Kräfte, Momente und Geschwindigkeiten an der Radaufhängung gelten die folgenden maximalen Werte:

Tabelle 2: Kräfte und Geschwindigkeiten IPS

\begin{tabular}{|l|l|}
\hline \multicolumn{1}{|c|}{ Parameter } & Wert \\
\hline Fz (Radlast) & $\operatorname{max.} 10.000 \mathrm{~N}$ \\
\hline Fy (Seitenkraft) & $\max . \pm 10.000 \mathrm{~N}$ \\
\hline Fx (Umfangskraft) & $\operatorname{max.} \pm 10.000 \mathrm{~N}$ \\
\hline Umfangsgeschwindigkeit des Prüfrades & $\operatorname{max.} 230 \mathrm{~km} / \mathrm{h}$ \\
\hline
\end{tabular}

Für die Genauigkeit der Meßeinrichtung gelten: 
Tabelle 3: Genauigkeit Kraftmessung

\begin{tabular}{|l|l|}
\hline \multicolumn{1}{|c|}{ Parameter } & Wert \\
\hline Fz (Radlast) & $\leq 1 \%$ im Meßbereich von 1000 bis $10000 \mathrm{~N}$ \\
\hline Fy (Seitenkraft) & $\leq 1 \%$ im Meßbereich von 1000 bis $10000 \mathrm{~N}$ \\
\hline Fx (Umfangskraft) & $\leq 1 \%$ im Meßbereich von 1000 bis $10000 \mathrm{~N}$ \\
\hline Linearitätsabweichung der Meßwerte & $\leq 1 \%$ im Bereich von 1000 bis $10000 \mathrm{~N}$ \\
\hline Übersprechen der Meßwerte & $\leq 2 \%$ im Bereich von 1000 bis $10000 \mathrm{~N}$ \\
\hline
\end{tabular}

Bild 24 zeigt eine Ansicht der konstruktiv ausgeführten Kraftmeßeinrichtung am Prüfstand IPS mit abgenommenem Rad und abgenommener Schutzabdeckung.

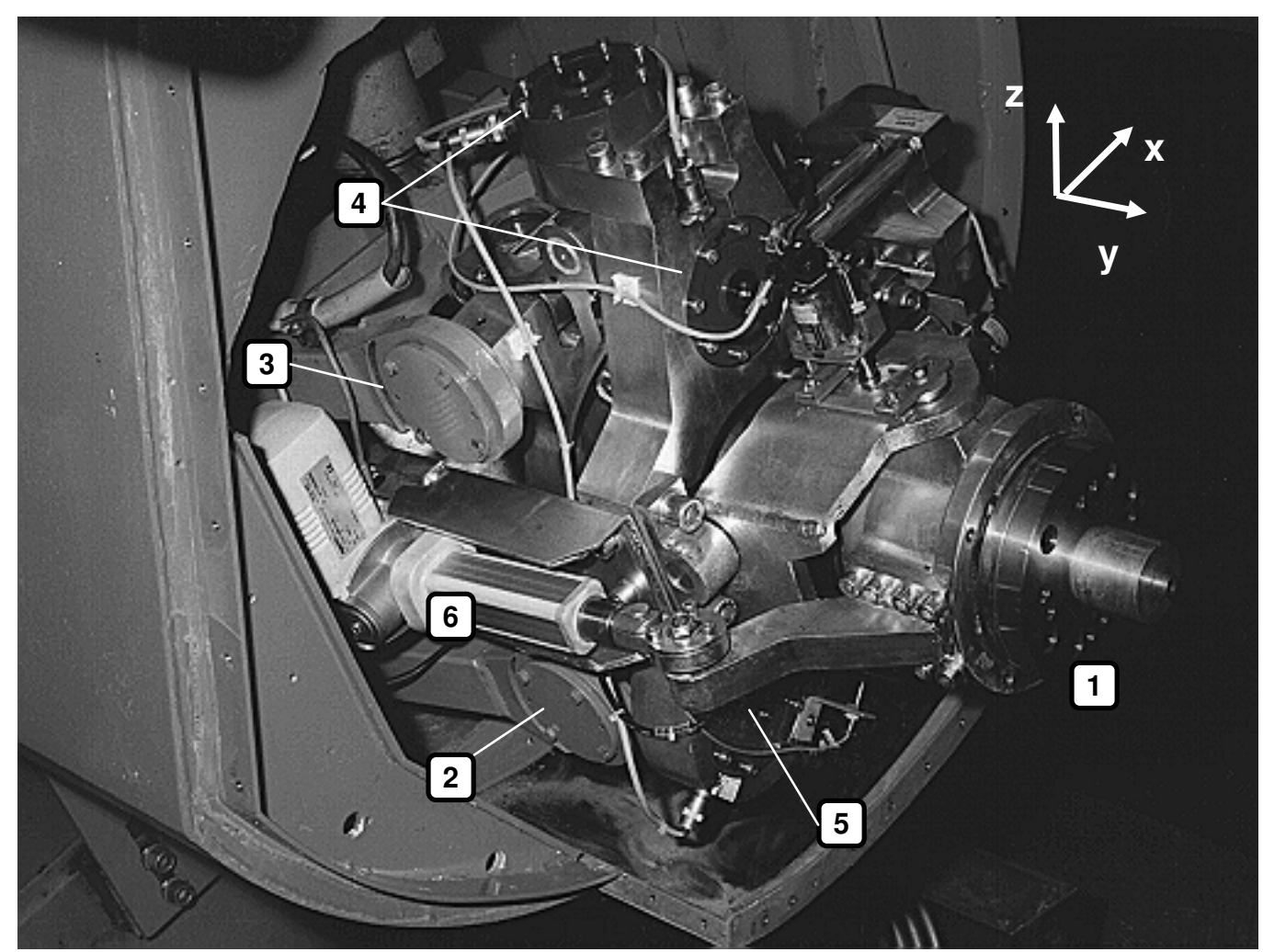

Bild 24: Radaufhängung zur Kraft- und Momentenmessung im Innentrommelprüfstad IPS - (1) Radnabe, (2) unterer Querlenker, (3) oberer Querlenker, (4) Kraftmeßdosen, (5) Kraftmeßdose, (6) Spurstangenantrieb

Die ausgeführte Konstruktion übertrifft die schematische Darstellung weit an Komplexität und Aufwand. Sie soll an dieser Stelle jedoch nicht vertieft erläutert werden. 


\subsection{Gleitvorgänge, Sensorik in Reifen und Fahr- bahn}

Für den Reibkraftaufbau am Pkw-Reifen sind neben den elastischen Verformungen, die mit den Darmstädter Reifensensoren gemessen werden können, die Gleitbewegungen zwischen den Profilelementen und der Fahrbahnoberfläche von entscheidender Bedeutung (vgl. Kapitel 1.2).

Zur Messung von Gleitvorgängen an Profilelementen eines abrollenden Reifens wurde im Rahmen dieser Arbeit ein neuartiges Verfahren entwickelt, mit dem auch die Reifensensorsignale in direkten Zusammenhang gebracht werden können. Bild 25 zeigt das Funktionsprinzip dieser Vorrichtung schematisch. Neben dem Reifensensor im Laufstreifen (hier: 2. Generation) befindet sich in der Fahrbahn ein zweiter Sensor, der die Bewegungen des einvulkanisierten Magneten relativ zur Fahrbahn mißt. Dieser Sensor erfaßt die elastischen Deformationen

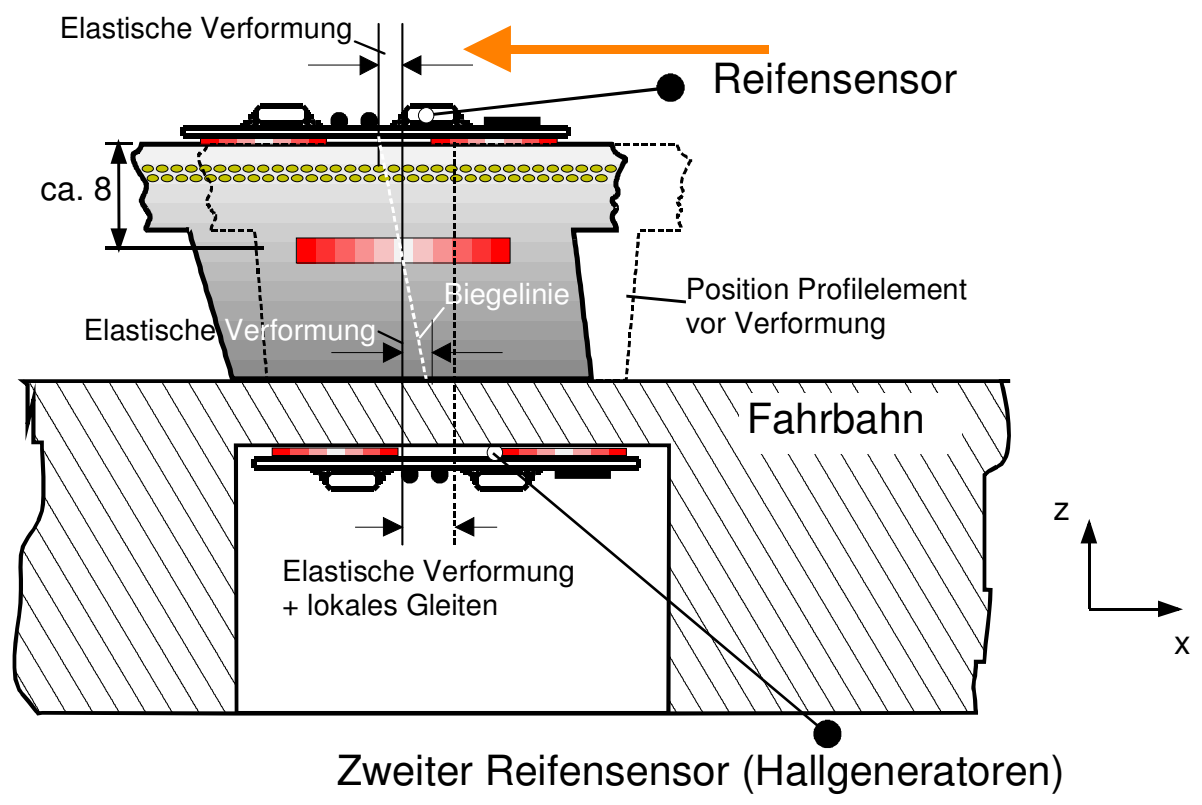
des Gummis zwischen

Bild 25: Vorrichtung zur Erfassung lokaler Gleitvorgänge am Prüfstand LINUS Magnet und Fahrbahn und zusätzlich die Wegstrecken, die durch lokale Gleitvorgänge zurückgelegt werden. Zur Trennung der elastischen Verformungsanteile von den Gleitanteilen im Fahrbahnsensorsignal kann das Reifensensorsignal auf die elastische Gesamtverformung extrapoliert werden. Mit Hilfe von vorangegangenen Kalibrierversuchen können die Anteile zuverlässig detektiert und getrennt werden (vgl. Kapitel 2.5).

Neben der Benutzung zusammen mit einem Reifensensor kann der Fahrbahnsensor auch zusammen mit kleinen Magneten verwendet werden, die sehr dicht an der Fahrbahnoberfläche im Reifengummi eingebracht sind. Dies gestattet die direkte Messung lokaler Gleitvorgänge ohne Deformationsanteile und kann zur Überprüfung des oben genannten Verfahrens dienen [39]. 
Das gezeigte Beispiel wurde in dieser Art am Prüfstand LINUS eingesetzt. Für die Randbedingungen an anderen Prüfständen wurde das Funktionsprinzip in geeigneter Weise abgewandelt.

Im Innentrommelprüfstand IPS der Bundesanstalt für Straßenwesen wird, ähnlich wie am Prüfstand LINUS, bei Versuchen immer wieder die gleiche Stelle vom Versuchsreifen überrollt. Im Unterschied zu LINUS kann hier jedoch nicht die Stelle am Reifenumfang vorher genau eingestellt werden, die später den in der Fahrbahn eingebetteten Sensor trifft. Um dennoch Messungen mit der Fahrbahnsensorik durchzuführen, muß eine so große Anzahl an Überrollungen stattfinden, daß im Rahmen der statistischen Wahrscheinlichkeit der Fahrbahnsensor getroffen wird. Um die Anzahl der notwendigen Überrollungen auf ein vertretbares Maß zu reduzieren, bietet es sich an, entweder die Anzahl der Sensoren in der Fahrbahn oder die der Sensoren im Reifen zu erhöhen. Für die in dieser Arbeit diskutierten Messungen wurde in Abwandlung des oben beschriebenen Prinzips eine Sensoranordnung gewählt, die sowohl die statistische Wahrscheinlichkeit eines Treffers erhöht, als auch mit möglichst wenig Sensoren auskommt, um den Aufwand für die Datenauswertung minimal zu halten. In Bild 26 ist das Funktionsprinzip der gewählten Anordnung dargestellt.

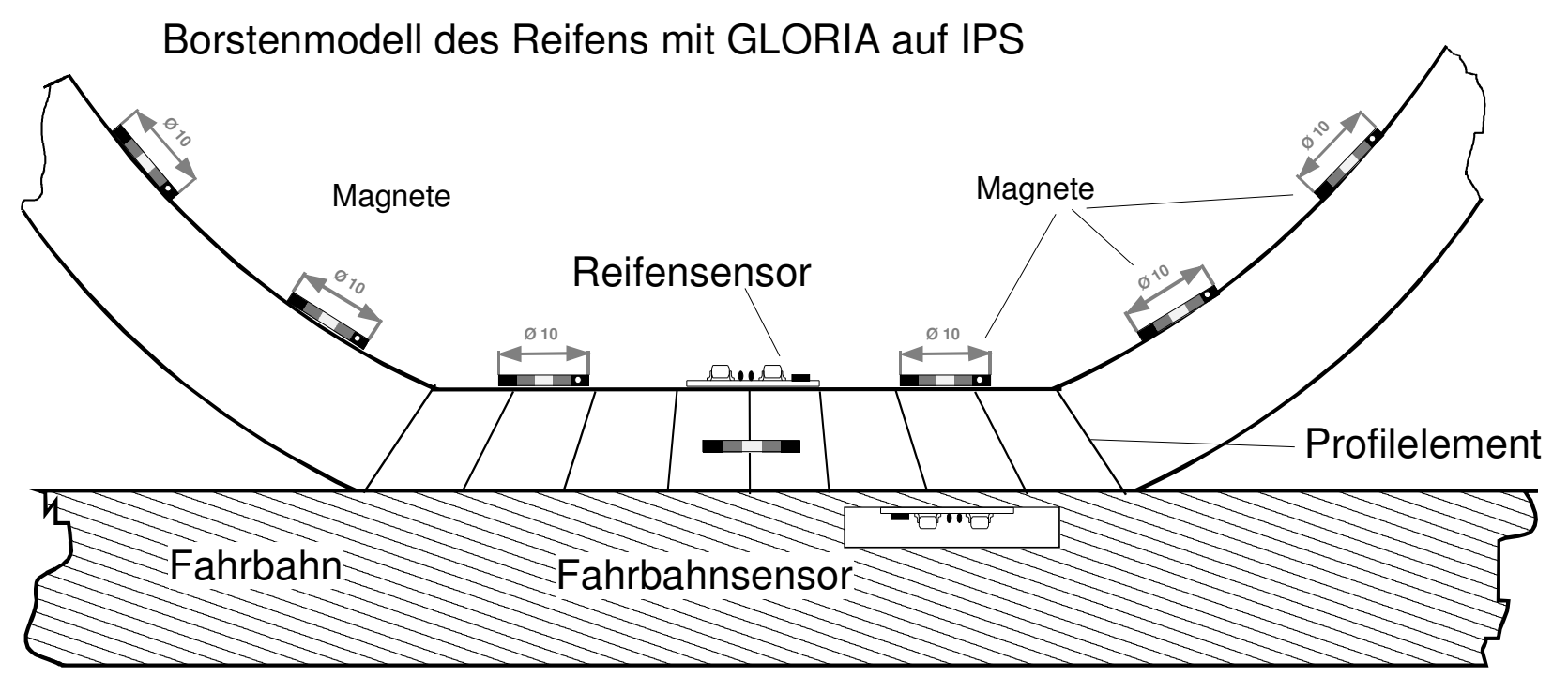

Bild 26: Meßanordnung zur Erfassung lokaler Gleitbewegungen am Prüfstand IPS

Der Reifensensor wird in seiner normalen Konfiguration verwendet und ermittelt die elastische Verformung der Profilelemente. Der Fahrbahnsensor ist in einer der asphaltgefüllten Kassetten des Innentrommelprüfstands eingebaut und soll die Bewegungen der Magnete, die an der Innenseite des Reifens angebracht sind erfassen. Damit kann die elastische Gesamtverformung der Profilelemente an der Stelle des Magneten zusammen mit den jeweils auftretenden Gleitbewegungen ermittelt werden. Aus dem Vergleich mit den Reifensensorsignalen, die nur den elastischen Verformungs- 
anteil widerspiegeln, ist die Isolation der Gleitbewegungen möglich. Nachteilig ist dabei, daß die Messung der Gleitbewegungen an anderer Stelle erfolgt als die Messungen mit dem Reifensensor. In Anbetracht der großen Zahl von Überrollungen während einer Messung im Innentrommelprüfstand und den sehr gut reproduzierbaren Fahrbahn- und Umgebungsbedingungen können dennoch repräsentative Reifensensorsignale gefunden werden, die mit den Fahrbahnsensorsignalen vergleichbar sind. Vorteilhaft ist bei dieser Lösung, daß durch das Anbringen von mehreren Magneten an der Innenseite des Reifens die Trefferwahrscheinlichkeit sehr einfach erhöht werden kann. Im gegebenen Fall konnten mit 19 Magneten auf der Reifeninnenseite bei ca. jeder 20. Trommelumdrehung Treffer erzielt werden.

Bild 27 zeigt eine Aufnahme der Fahrbahnkassette des Innentrommelprüfstands, in der die Fahr-

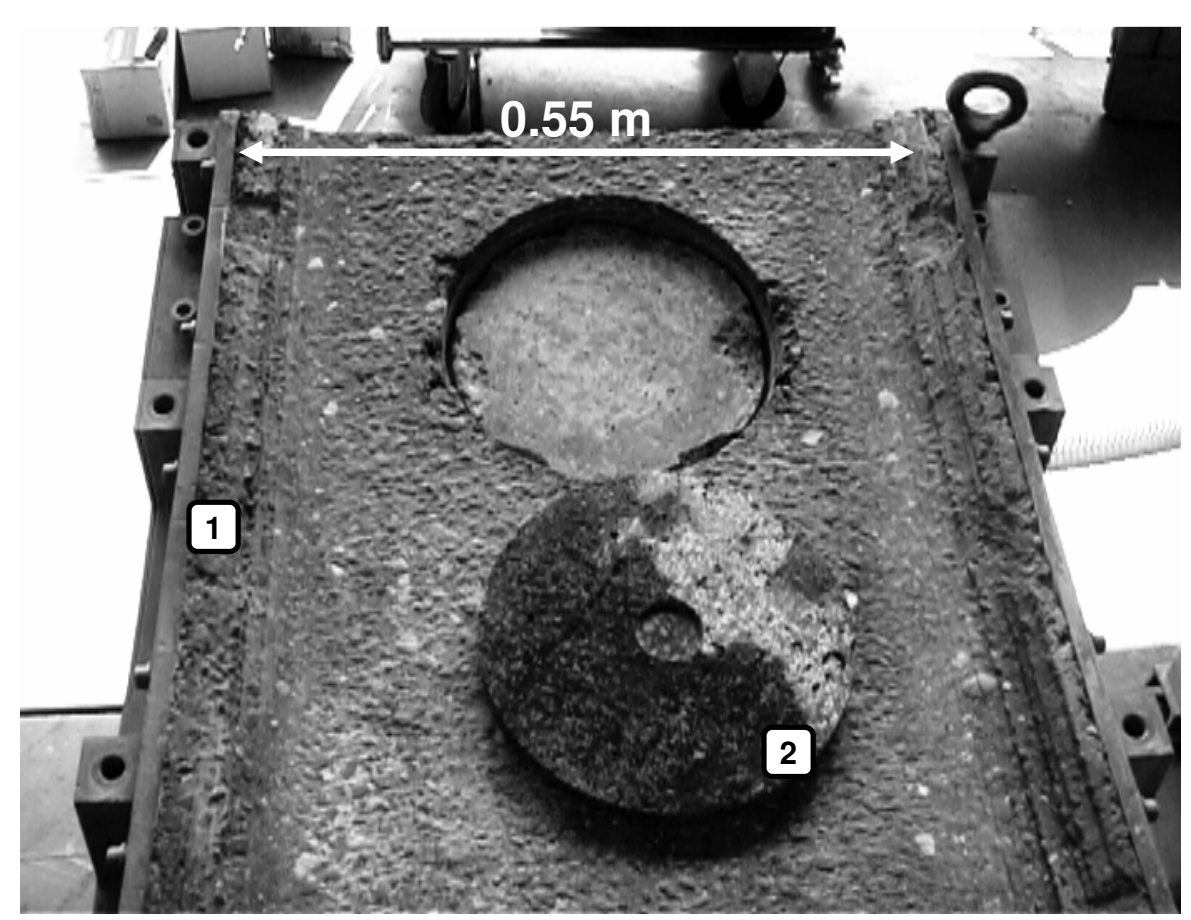

Bild 27: Montage des Fahrbahnsensors in einer Fahrbahnkassette (1) des Prüfstands IPS , (2) Fahrbahnausschnitt mit rückseitiger Öffnung zur Aufnahme des Sensors bahnsensorik eingebaut wurde. Ein kreisrundes Teil der Asphaltdecke mit einem Durchmesser von $20 \mathrm{~cm}$ wurde mit einem Kernbohrer ausgeschnitten und entfernt. Die Rückseite dieses Deckels wurde mit einer Öffnung versehen, in die der Fahrbahnsensor eingebaut wurde. Danach wurde der Ausschnitt wieder in die Fahrbahn eingesetzt, mit Silicon abgedichtet und mit Bitumenmasse vergossen. Die Übertragung der Meßdaten des Sensors aus der rotierenden Trommel erfolgte mit einer berührungslosen Datenübertragung der Firma DATATEL, die bereits in früheren Untersuchungen zur Übertragung der Reifensenorsignale im fahrenden Fahrzeug von Stöcker [112] genutzt wurde. Die Energieversorgung der Hallgeneratoren stellten Batterien sicher. 


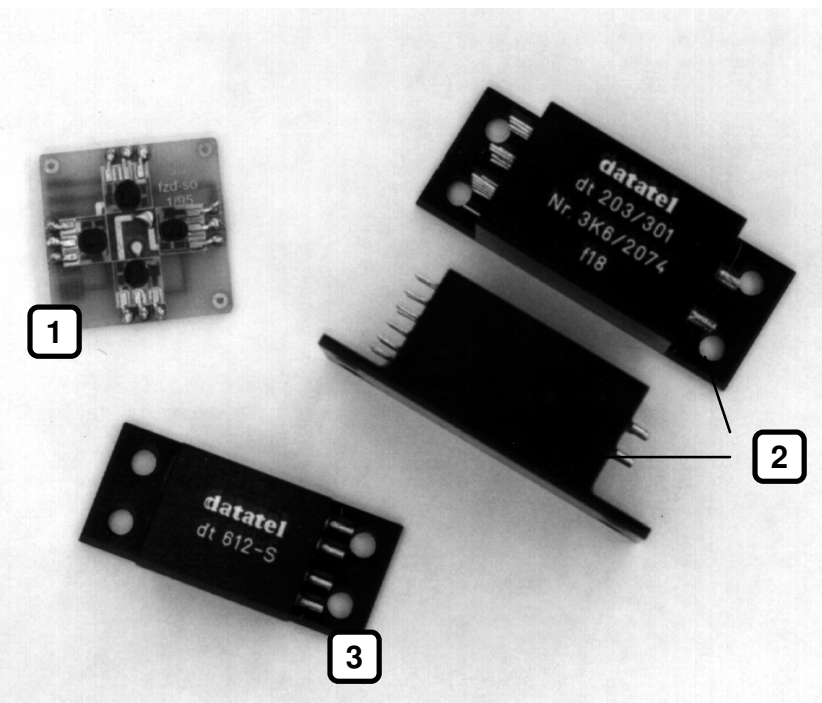

Bild 28 zeigt die Komponenten der

Telemetrie zusammen mit einer Platine des Sensor der 2. Generation, wie sie als Reifensensor und als Fahrbahnsensor eingesetzt wurde.

Zur Funktion der Sensorik und zur Interpretation der verschiedenen Signale sind Kalibrierversuche im Vorfeld nötig, die in Kapitel 2.5 besprochen werden.

Bild 28: Komponenten der telemetrischen Datenübertragung - (1) Sensorplatine, (2) Verstärkermodule, (3) Hochfrequenzsender

\subsection{Standardbedingungen}

Für alle in dieser Arbeit diskutierten Versuche gelten Standardbedingungen, unter denen, wenn nicht anders erwähnt, die jeweiligen Messungen stattgefunden haben. Tabelle 4 enthält eine Auflistung der Standardparameter.

Tabelle 4: Standardparameter

\begin{tabular}{|l|l|l|}
\hline \multicolumn{1}{|c|}{ Parameter } & Wert LINUS & Wert IPS \\
\hline Radlast & $2500 \mathrm{~N}$ & $2500 \mathrm{~N}$ \\
\hline Schräglaufwinkel & $\pm 0^{\circ}$ & $\pm 0^{\circ}$ \\
\hline Sturzwinkel & $\pm 0^{\circ}$ & $\pm 0^{\circ}$ \\
\hline Geschwindigkeit & $0.0147 \mathrm{~m} / \mathrm{s}$ & $11,11 \mathrm{~m} / \mathrm{s}(40 \mathrm{~km} / \mathrm{h})$ \\
\hline Fahrbahn & Acrylglas & Asphaltbeton $0 / 11$ \\
\hline Fahrbahnzustand & trocken & Nass, 2mm Wasserfilm \\
\hline Versuchsreifen & Pirelli P 700 Z & Pirelli P 700 Z \\
\hline Reifendimension & $205 / 50 \mathrm{R} 1586 \mathrm{~V}$ & $205 / 50 \mathrm{R} 15 \mathrm{g6} \mathrm{V}$ \\
\hline Reifeninnendruck & $2.5 \mathrm{bar}$ & $2.5 \mathrm{bar}$ \\
\hline Profiltiefe & $7 \mathrm{~mm}$ & $7 \mathrm{~mm}$ \\
\hline
\end{tabular}

